\title{
UNIDAD DE HECHO EN EL CONCURSO IDEAL
}

Unity of facts in concurrent offenses

\author{
FRANCISCO MALDONADO FUENTES ${ }^{1}$ \\ Universidad de Talca
}

\begin{abstract}
RESUMEN
El texto analiza la noción de "unidad de hecho" en el ámbito del concurso ideal de delitos. Pasa revista a las tesis que configuran dicho concepto en base a criterios propios de la realidad empírica (como el contexto, lapso de tiempo o referencia a un lugar); a los resultados, intensiones o motivos; a la definición de delito o a características adicionales y externas como la indivisibilidad o evitabilidad de los delitos concurrentes. Dichas alternativas se descartan por su falta de coherencia interna; por su incompatibilidad con el propio supuesto del concurso ideal o, finalmente, porque no ofrecen razones idóneas para explicar el tratamiento penológico asignado a dicha hipótesis. Se descarta asimismo la opción de prescindir de la distinción (concurso real e ideal) por cuanto se da cuenta de antecedentes históricos, escasamente trabajados en la literatura, que explican cómo la distinción se explica por la consideración del "concurso real" como un caso de reiteración delictiva. Por ello, se sostiene la tesis de que la unidad de hecho propia del concurso ideal se expresa en la identificación de un sustrato en el que coincide la realización de dos o más delitos y que tiene la particularidad de que ofrece un supuesto que expresa o refleja un único acto o manifestación de voluntad contrario a derecho.
\end{abstract}

\section{PALABRAs CLAVE}

Concurso ideal de delitos, unidad de hecho, reiteración delictiva.

\section{ABSTRACT}

This article analyzes the different ways to interpret a basic case of concurrent offenses. This article examines different legal theories to explain these cases. The theories are focused on different aspects: the empirical reality (related to the context, time, and place where the crime was committed); subjective matters (such as intention or motivation); theories focused on the connections between the elements of the crimes involved (generally related to the ideas of indivisibility, necessity or avoidance). These proposals are criticized by its internal coherence, considering their problems to conceptualize and propose solutions distinguishing cases that require different penalties. In this regard, this article criticizes the proposal that rejects the distinction between unity and plurality of facts in a concurrent offenses, considering historical reasons and its current application. The article's proposal is constructed based on the idea of identifying common characteristics of the perpetration of crimes.

\section{KEYWORDS}

Ideal crime concurrence, unit of fact, recidivism.

\section{Introducción}

Las legislaciones suelen diferenciar los supuestos de concurso de delitos según si las realizaciones delictivas se han ejecutado en unidad o pluralidad de hechos o de acciones, afirmándose un concurso ideal de delitos en el primer caso y un concurso real o material en el segundo ${ }^{2}$. La categorización se justifica en todos los casos pues se asigna a cada categoría un

\footnotetext{
${ }^{1}$ Abogado. Doctor en Derecho. Profesor Asociado de la Facultad de Ciencias Jurídicas y Sociales de la Universidad de Talca, Talca, Chile. Correo electrónico: franciscomaldonado.2006@gmail.com. El texto forma parte del proyecto Fondecyt Regular №1170276, financiado por Conicyt, del cual el autor es investigador responsable.

${ }^{2}$ Como excepción se menciona Estados Unidos y el abandono de la distinción en Francia, Portugal, Austria y Suiza. MAÑALICH (2005), p. 1150; SUÁREZ (2001), p. 53; STRATENWERTH (2005), p. 549; SANZ (1986), pp. 57 y ss.
} 
tratamiento penológico diverso, menos riguroso en el concurso ideal. El caso chileno no es la excepción pues el concurso ideal se sanciona bajo un régimen de absorción agravado (con la pena mayor asignada al delito más grave) confirme dispone el artículo 75 del Código Penal, mientras que el concurso real se trata por regla general bajo un régimen de acumulación de sanciones (art. 74 del Código Penal) y, excepcionalmente, de exasperación, cuando se trata de delitos que afectan al mismo tipo de bienes jurídicos (conforme a los casos y formas previstos en el artículo 351 del Código Procesal Penal).

Este amplio e histórico reconocimiento no se acompaña sin embargo de claridad ${ }^{3}$, pues se discute ampliamente qué cabe considerar como unidad de hecho o unidad de acción y por qué se asocia a un régimen privilegiado ${ }^{4}$. De hecho, en la actualidad prima la idea de que no existen razones atendibles para diferenciar ambos casos a efectos de asignar regímenes sancionatorios diversos ${ }^{5}$. En este sentido, no es sencillo resolver si actúa en unidad de hecho quien percuta tres disparos sobre tres víctimas fatales en un mismo contexto espacio-temporal $y$, en especial, por qué debe recibir menos pena que quien provoca las mismas muertes en tres momentos diversos de un mismo día ${ }^{6}$.

Las interpretaciones propuestas son múltiples y bastante disímiles. Por un lado, están las llamadas perspectivas "pre-jurídicas" o "naturalísticas" referidas a quienes identifican la unidad de hecho con criterios propios de la realidad material u "ontológica" (conforme a la terminología tradicional); por otro, quienes adscriben dicha determinación a una conceptualización previa estructurada en base a las definiciones de lo que cuenta como acción en términos generales o a partir de las descripciones típicas; y quienes identifican dicha unidad con una misma y única motivación o finalidad ${ }^{7}$. Finalmente, la doctrina dominante se inclina por vincular el supuesto del concurso ideal de delitos con los casos en que las diversas infracciones presentan una relación de dependencia o "necesidad", descartando la unidad de hecho en los supuestos en que la ejecución conjunta o separada se advierte como una opción voluntaria del infractor. Bajo esta perspectiva lo determinante es el carácter indivisible de la ejecución conjunta (el que no haya podido ejecutarse un delito sin el otro) y no la advertencia de un determinado contexto espacio-temporal; de uno o varios "resultados" de la acción o de una determinada conexión motivacional entre los distintos ilícitos cometidos. La tesis $-\mathrm{y}$ su amplia acogida en nuestro medio ${ }^{8}$ - se vincula directamente a los argumentos propuestos por Pacheco sobre el texto del Código Penal español de $1848^{9}$, cuya influencia en la génesis de la regulación criolla es conocida. Lo relevante es tener en cuenta que el privilegio asociado a la pena del concurso ideal no se justifica en quienes simplemente han "escogido" un medio masivo o unificado para causar una pluralidad de lesiones, pues en dichos casos la voluntad que se reprocha no sería distinta a la que se advierte en cualquier otro caso de realización "independiente" de varios delitos ${ }^{10}$. Por el contrario, en los casos en que la ejecución conjunta se muestra indivisible si se podría sostener dicho tratamiento más beneficioso pus concurriría un déficit en la voluntariedad que habilita a un reproche atenuado de la culpabilidad. Así, la atenuación se reservaría para quien "decide" matar a una mujer embarazada pues no ha podido "evitar" provocar "además" el aborto, en

\footnotetext{
${ }^{3}$ Por todos, VAN WEEZEL (2020), p. 2.

${ }^{4}$ Ambas cuestiones (diversas) están íntimamente relacionadas pues carece de sentido una interpretación que no fundamente el efecto previsto en la respectiva disposición, al margen del análisis sobre su conveniencia o justificación político criminal. Sobre ello MALDONADO (2016b), pp. 557-561.

${ }^{5}$ En Chile, por todos, GARRIDO (2007), p. 350; para España, SUÁREZ (2001), pp. 51 y ss.; ESCUCHURI (2004), pp. 90-91. Sobre Alemania, FRISTER (2016), p. 667.

${ }^{6}$ CARUSO (2018), p. 18; ROIG (2011), pp. 120 y ss.

7 En la literatura comparada se identifica una cuarta orientación asociada al "parentesco del injusto" (atribuida a Puppe), vinculada el ne bis in ídem y que, en general, es rechazada. Por todos, ROXIN (1997), pp. 963-965; ESCUCHURI (2004), pp. 232-238.

${ }^{8}$ GARRIDO (2007), p. 350; ETCHEBERRY (1997), p. 120; LABATUT (1983), p. 173; MUÑOZ (1986), p. 359 y 362.

${ }^{9}$ PACHECO (1888), pp. 421-423; ETCHEBERRY (1997), p. 120; GARRIDO (2007), p. 350; LABATUT (1983), p. 173.

${ }^{10}$ Lo más relevante es que lo dicho lleva a descartar que el criterio se vincule a la mera simultaneidad de los delitos, pues si así fuese la pena aplicable al caso (privilegiada) terminaría dependiendo de una opción o de la mera voluntad del infractor, lo que resultaría absurdo o inaceptable. En este sentido, ROIG (2011), pp. 120 y ss. CARUSO (2018), p. 18.
} 
aquellos casos en que este último delito no formara parte del contenido esencial de su pretensión delictiva ${ }^{11}$.

En esta contribución sostendremos la insuficiencia de cada una de estas perspectivas, incluyendo a esta última; sea por razones de coherencia interna, por su incompatibilidad con el propio supuesto del concurso ideal o porque a fin de cuentas no ofrecen razones idóneas para explicar el tratamiento penológico privilegiado. Descartaremos también la opción de prescindir de la distinción (concurso real e ideal) pues daremos cuenta de antecedentes históricos escasamente trabajados en la literatura- que parecieran suficientes para explicarla y justificarla, con base en la relación que es posible de construir entre la pluralidad de hechos o acciones y la reiteración delictiva.

\section{Precisiones preliminares fundamentales sobre la unidad de hecho y la unidad de acción en la teoría del concurso de delitos}

Antes de entrar al fondo conviene dejar constancia de algunas precisiones fundamentales de carácter preliminar. La temática se trata indistintamente en torno a la "unidad de hecho" y la "unidad de acción" lo que suele ser fuente de confusiones. En efecto, no siempre es claro si se trata de referencias exactas, si se alude a cosas distintas o si ambas nociones son tratadas como equivalentes. Por lo demás, se trata de términos que admiten una amplia gama de lecturas diferentes. Hay que tener en cuenta, en primer lugar, que parte de las legislaciones ocupan la unidad de hecho y otras la unidad de acción como presupuesto del concurso ideal (en Chile y en España, "un hecho", y en Alemania "la misma acción") de forma que no es extraño que las respectivas interpretaciones atiendan a algo diverso. En segundo lugar, se debe puntualizar que el contenido atribuido no siempre es diverso, a pesar de que "hecho" parece dar cuenta de una noción más amplia que la expresión "acción" pues dicha noción incluiría además al resultado o a otros elementos típicos (adicionales) ${ }^{12}$.

A dicho respecto no hay que olvidar que lo que cuenta como una acción es algo ampliamente controversial, tanto en términos generales ${ }^{13}$, como cuando el derecho requiere acudir a dicha determinación ${ }^{14}$. Los escasos consensos reconocen que dicha tarea depende de una descripción ${ }^{15}$ y supone por ello una operación de interpretación ${ }^{16}$. Quien se desplaza al volante en un vehículo motorizado mueve las manos, los pies, la cabeza, conduce, viaja y asiste a una determinada reunión, todo a la vez e indistintamente, siendo correcta o incorrecta la perspectiva que se asuma según cual fuere el sentido que inspira y motiva la aproximación ${ }^{17}$. Esta aclaración basta para descartar los criterios extraídos del contexto naturalístico o "prejurídicos", por la sencilla razón de que carecen de una dimensión de sentido. De ahí que ofrezcan resultados indeterminados e imprecisos en todos los $\operatorname{casos}^{18}$.

En este contexto, cobra sentido sostener que lo que cuenta como acción para al derecho penal debiese depender de las definiciones que ofrezca el propio legislador en cuanto a los comportamientos que resultan relevantes en materia penal ${ }^{19}$. Así, percutar el gatillo de un arma direccionada a un tercero cuenta a estos efectos como una "acción de matar" y resulta irrelevante como fenómeno neuromuscular o como expresión genérica de comportamiento

\footnotetext{
${ }^{11}$ ARCE (1996), pp. 72 y ss.

12 BUSTOS (1962), pp. 37 y 84; ETCHEBERRY (1997), p. 119; NINO (1972), p. 30 y ss. (crítica en pp. 32 y 33); ROXIN (1997), p. 944; FERNÁNDEZ (2013), p. 37.

${ }^{13}$ ZAFFARONI et al. (2002), p. 856.

${ }^{14}$ GONZÁLEZ (2015) pp. 66-69; FRISTER (2016), p. 690.

${ }^{15}$ CID (1994), p. 49; FRISTER (2016), p. 669.

16 MEZGER (1955), p. 362 (quien califica a este proceso como "valorativo"). Por ello, la unidad de hecho debe corresponder a una aproximación intensional. MAÑALICH (2018b), pp. 105-131. Sobre la diferencia entre la descripción intensional y extensional, en general, GARCÍA (1995), pp. 149-150; el propio MAÑALICH (2018c), pp. 185 y ss.; y OSSANDON (2018), p. 966.

17 SILVA (2003), pp. 56 y 63

${ }^{18}$ CUERDA (1997), pp. 346-347; ARCE (1996), p. 60; CARAMUTI (2018), p. 37; SUÁREZ (2001), p. 74; ESCUCHURI (2004), pp. 368 y 374; VAN WEEZEL (2021), p. 316.

${ }^{19} \mathrm{CID}$ (1994), pp. 48-49. Como indica RADBRUCH (2011), p. 110: “Que el delito es una acción, no le interesa en primer lugar (en referencia a Liszt); que es una acción de cierta índole, eso representa el punto de partida de la reflexión". Implícito, en POLITOFF (2003), p. 445.
} 
humano. Por ello parecería lógico sostener que la posibilidad de identificar en un supuesto de hecho la concurrencia de una acción -en este sentido- depende en definitiva de la eventualidad de que en el mismo se satisfagan los elementos (propiedades) con que se describe dicho modo de actuar en particular. Incluso más, si dicha noción depende de todo lo que la define en cuanto tal $^{20}$, cobra incluso sentido el considerar la concurrencia de una determinada acción a partir del resultado que provoca, pues no hay "acción de matar" si no se constata la muerte de alguien ${ }^{21}$. Con ello parece claro que las nociones de acción y hecho se asimilan, en tanto se trata de nociones relativas a un mismo tipo de conceptualización ${ }^{22}$, como también el que bajo esta aproximación el contenido de ambos conceptos resulta equivalente o idéntico al que da forma al correspondiente delito. Volveremos sobre esto último más adelante.

No obstante, lo dicho nos permite por ahora incorporar la consideración de un elemento de juicio adicional, relativo al papel determinante que cumple la funcionalidad que subyace $y$ motiva a la respectiva definición ${ }^{23}$. Así, con la selección de las propiedades típicas de un delito se busca precisar un tipo de hecho (punible) en tanto merecedor de sanción penal, mientras que su valoración como un "acto con sentido" se determina por condicionantes distintas y más genéricas (como acción o comportamiento), en cuanto se trata de una conceptualización que solo buscan dar cuenta de condicionantes mínimas para un juicio de imputación ${ }^{24}$. Así se explica por qué lo que se afirma tras la acción como conducta y tras acción típica (o la propia tipicidad, en general), sea algo diverso ${ }^{25}$. Lo dicho es fundamental, pues permite advertir que la noción de unidad de acción o unidad de hecho no necesariamente es utilizada de forma unívoca en derecho penal y, según veremos, tampoco en el ámbito concursal.

En este sentido es claro que la unidad de hecho o de acción en el campo de la teoría del delito y en determinados supuestos problemáticos propios de la teoría concursal, cumple concretamente funciones relativas a la cuantificación de los delitos concurrentes (afirmar o negar la ejecución de un único o de varios delitos o "contar delitos"), en cuyo caso dichas nociones presentan una asociación o nexo más fuerte o estrecho con la definición de lo que cuenta como delito ${ }^{26}$. Así sucede cuando se aborda la compleja cuestión de identificar una unidad de ejecución en una sucesión de acontecimientos similares relativos a un mismo tipo de delito (ejecución sucesiva, iterativa o progresiva del mismo y único delito) ${ }^{27}$ a fin de descartar o afirmar un concurso real homogéneo, tratados como casos unidad de acción (natural o jurídica ${ }^{28} y$, en extremos, en torno a los límites del delito continuado ${ }^{29}$.

\footnotetext{
${ }^{20}$ RADBRUCH (2011), p. 110.

${ }^{21}$ NINO (1972), pp. 32 y 37; MAÑALICH (2014), pp. 32 y ss.

${ }^{22}$ BUSTOS (1962), pp. 35 y ss.

${ }^{23}$ GONZÁLEZ (2015), p. 73.

${ }^{24}$ RADBRUCH (2011), p. 117; Sobre ello, SILVA (2003), pp. 52 y 59-61 (crítica en pp. 61-63). Más general, FLETCHER (2008), p. 363.

25 SILVA (2003), pp. $46-47$ y 51 (la pregunta y el contenido, en ambos casos, es diverso).

${ }^{26}$ Constituye por ello una tarea que demanda una adecuada interpretación de parte especial. ESCUCHURI (2004), p. 252; FERNÁNDEZ (2013), p. 28; CUELLO (1979), p. 48. Sin embargo, hay que tener en cuenta que ello no basta, pues para identificar una unidad (unicidad) o pluralidad se requiere de un ejercicio adicional. Por otro lado, lo dicho permite advertir que sostener, con la doctrina dominante, que la noción de "acción" en la teoría concursal constituye algo diverso a la consideración que ofrece dicha noción en el ámbito de la teoría del delito es algo solo parcialmente correcto. Por todos, JAKOBS (1997), p. 1074; SANZ (2012), p. 40; PALMA (2004), p. 110; POSADA (2008), p. 80; ROXIN (1997), p. 944.

${ }^{27}$ La terminología y casos es variada. Se cuenta la ejecución iterativa ("ejecución homogénea equivalente reiterada en tiempo próximo") la "ejecución sucesiva ("continuidad de actos que admite ser dividida en etapas"), los "delitos de acción múltiple homogénea" (acciones prolongadas o descripciones plurales como la "pertenencia a una organización", el "suministro de información" o la "falsificación de moneda") y la ejecución progresiva (cuando se "incrementa la gravedad objetiva del hecho" o la lesión "va de menos a más". Al respecto JESCHECK Y WEIGEND (2014), p. 1063; MAÑALICH (2005), p. 1031; WESSELS et al. (2018), p. 539; ROXIN (1997), pp. 947-954; ORTIZ Y ARÉVALO (2013), p. 320; MIR (2005), p. 627; CARUSO (2018), pp. 27 y 28.

${ }^{28}$ GARRIDO (2007), p. 338. En el contexto alemán se usa a dichos efectos la unidad natural de acción (como descripción asociada a una determinada descripción típica). FRISTER (2016), p. 672 (como "unidad de sentido social") y JESCHECK Y WEIGEND (2014), p. 1063 ("unidad típica de acción en sentido amplio"); o WESSELS et al. (2018), p. 535. Así, su calificación "natural" no alude a una dimensión física, empírica o pre jurídica, sino a una noción normativa o jurídica (STRATENWERTH (2005), p. 536; GARCíA (1995), p. 12; CARUSO (2018), p. 25), que se critica profusamente por razones de indeterminación, arbitrariedad y vaguedad (STRATENWERTH (2005), p. 537). Sobre los usos lingüísticos a este respecto, con carácter general, ROXIN (1997), pp. 945 y ss. (especialmente, p. 950); FRISTER (2016), p. 669; WESSELS et al. (2018), p. 537.

${ }^{29}$ En el mismo sentido MAÑALICH (2018c), p. 174. Sobre el fondo MALDONADO (2015), pp. 216 y ss. Asimismo, con detalle,
} MALDONADO (2020), pp. 742 y ss. 
Lo relevante es que dicha determinación se presupone agotada en los casos de concurso ideal pues lo que cuenta como hecho o como acción a estos efectos debe corresponder a un contenido que resulte compatible con la afirmación de una pluralidad de infracciones, de forma que en caso alguno podría llegar a identificarse con el contenido de las mismas ${ }^{30}$. En este sentido, si dicha definición dependiera de las propiedades definitorias de los correspondientes delitos se deberían siempre afirmar tantas acciones o hechos como delitos constatados, de forma de sería conceptualmente imposible identificar un concurso de delitos en unidad de acción o de hecho ${ }^{31}$. Por ello, se sostiene con razón que acción y delito no son ni pueden ser "lo mismo", al menos a este respecto ${ }^{32}$. Cabe recordar -y aquí está la relevancia concreta de la dimensión funcional que pretendemos destacar- que en el campo del concurso ideal la constatación de una unidad de hecho o de acción sirve en exclusiva a los efectos de diferenciar dicha categoría de los supuestos de concurso real, cuyo único efecto se vincula -según ya hemos visto- a la asignación de un tratamiento penológico diferenciado ${ }^{33}$. Se trata por ello de una determinación circunscrita al ámbito propio de la determinación de la pena ${ }^{34}$, donde no es relevante lo que el delito es, sino la forma como se debe reaccionar frente al mismo ${ }^{35}$.

Lo dicho es altamente relevante. Primero, pues permite descartar el papel medular que se suele atribuir a la distinción (unidad o pluralidad de hecho o acción) en las definiciones esenciales del concurso de delitos ${ }^{36}$, pues, más allá de lo dicho (esto es, para la precisión de los casos de unidad natural de acción y, en especial, para la definición del presupuesto propio del concurso ideal de delitos) todo indica que carece de utilidad ${ }^{37}$. Pero además, pues pone en evidencia que la tendencia habitual de utilizar nociones estructuradas para alguna de esas tareas a efectos de resolver los problemas que propone la otra constituye un proceder erróneo ${ }^{38}$, por la sencilla razón de que se trata de conceptos diversos, que responden a objetivos y funciones diferentes ${ }^{39}$. Por ello es habitual que en ciertos casos el uso de un concepto se muestre equívoco, inútil, impreciso o que lleve a conclusiones erróneas.

\section{3. ¿Qué se entiende por unidad de hecho en el concurso ideal?}

\subsection{Aproximación pre jurídica (o "naturalística")}

\footnotetext{
${ }^{30}$ SANZ (1986), p. 148. Sobre esta base se sostiene que es un error frecuente confundir el análisis de la unidad de hecho con la unidad de delito. NÚÑEZ (1986), p. 12. Muy claro, MAÑALICH (2005), p. 1027 y 1034 (la relevancia de la "unidad de acción" es diferenciar el concurso ideal del real y no se refiere a determinar cuándo hay concurso).

${ }^{31}$ CUERDA (1997), pp. 341 a 354; JAKOBS (1997), p. 1079; SUÁREZ (2001), p. 74; PESSOA (2018), p. 66; ZAFFARONI et al. (2002), p. 857; VIVES (1981), p. 10; MAÑALICH (2005), p. 1150; SANZ (1986), p. 213; JESCHECK Y WEIGEND (2014), p. 1060. Implícito en el desarrollo de VAN WEEZEL (2021), pp. 309-311. Lo propio se puede afirmar, en los mismos términos, de la unidad de acción como expresión de comportamiento humano. Al respecto NINO (1972), p. 43.

${ }^{32}$ MIR (2005), p. 624.

${ }^{33}$ Por sobre ello se menciona en el contexto alemán una "función de clarificación", asociada a la supuesta necesidad de evidenciar la concurrencia de varios tipos penales. Sobre ello véase JESCHECK Y WEIGEND (2014), p. 1073; STRATENWERTH (2005), p. 552 y WESSELS et al. (2018), pp. 550 y 551. La aclaración fue relevante en la literatura tradicional pues se sostuvo profusamente en la primera mitad del siglo XX la idea de que una acción o conducta solo es captada en su desvalor a través de una única calificación delictiva. Así, la llamada "teoría de la unidad" (por todos MEZGER (1955), p. 378 -con crítica del traductor en nota al pie-) explica por qué la calificación de esta clase de concurso (la "concurrencia" de varias infracciones) se adscribe al plano de lo "ideal" por oposición a la realidad material. Al respecto, por todos, ROXIN (1997), p. 941; LURATI (2018), p. 118. Se parte de la base de que el delito "es la acción física" ejecutada en el ámbito empírico, como se destaca en BUSTOS (1962), pp. 32 y ss.; CARAMUTI (2018), pp. 33, 35 y 209; ETCHEBERRY (1964), pp. 11-12; FRISTER (2016), p. 666; JESCHECK Y WEIGEND (2014), p. 1073. Esta función ha perdido caso toda relevancia en la actualidad. Con más detalle, CASTELLÓ (2000), p. 35; ESCUCHURI (2004), pp. 198-200.

${ }^{34}$ Muy claro, recientemente, VAN WEEZEL (2021), p. 309.

${ }^{35} \mathrm{En}$ el fondo la identificación de una unidad de acción o de hecho sirve a dos finalidades diversas en el plano concursal. $Y$ en ambas ofrece un contenido también diverso. CARAMUTI (2018), p. 40; MAÑALICH (2018a), pp. 83-84; CARUSO (2018), pp. 23-24; GARCÍA (1995), p. 121

${ }^{36}$ GARRIDO (2007), p. 336; JESCHECK Y WEIGEND (2014), p. 1059; MEZGER (1958), p. 333 (muy categórico); ROXIN (1997), p. 943; próximo, WESSELS et al. (2018), p. 534. En España, por todos, CUERDA (1997), pp. 344-345 y, en el contexto latinoamericano, ZAFFARONI et al. (2002), pp. 853 y 854. Sobre lo extendido de dicha opinión véase CUELLO (1979), p. 50; ESCUCHURI (2004), p. 95.

${ }^{37}$ GARCíA (1995), p. 121; CARUSO (2018), pp. 23 y 24; ESCUCHURI (2004), pp. 354-355. Con menor precisión CARAMUTI (2018), p. 40.

${ }^{38}$ Se constata en MAURACH et al. (1995), p. 525; FRISTER (2016), pp. 669 y 673; CUERDA (1997), pp. 353 y 354 entiende que la confusión se explica por la primacía histórica que tuvo la llamada teoría de la unidad (el concurso ideal hay un solo delito) estructurada en torno al hecho de que en dichos casos se aplica una sola pena.

${ }^{39}$ CARUSO (2018), pp. 23 y 24; ESCUCHURI (2004), p. 376; GARCíA (1995), p. 121; MAÑALICH (2018a), pp. 83-84; ZAFFARONI et al. (2002), p. 857; VAN WEEZEL (2021), pp. 309-314. Con menor precisión CUERDA (1997), pp. 353 y 354.
} 
Toda aproximación a una acción o hecho procura la circunscripción o delimitación de un determinado acontecimiento. De ahí su nexo con un fragmento de la realidad ${ }^{40}$. Así se explica la intuitiva, clásica y dominante (hasta hace poco) tendencia a utilizar una aproximación empírica o naturalística ("pre-jurídica") a la hora de abordar una conceptualización ${ }^{41}$.

Tras ello se pierde de vista que el componente natural o empírico no es más que el supuesto que sirve de sustrato a la afirmación de una acción o hecho, sobre el que se deben identificar los contenidos o propiedades que hacen que una acción o hecho sea tal. Por ello, la determinación e identificación de aquello que cuenta como una determinada acción o hecho constituye un proceso que se alimenta de una dimensión conceptual que determina sus propiedades definitorias ${ }^{42}$. Responde a una definición.

A dicho respecto los criterios naturalísticos presentan una doble indeterminación: primero, pues cada suceso plantea una pluralidad de dimensiones de sentido que pueden ser relevantes de forma que su significado estará condicionado (siempre) por la aproximación del intérprete ${ }^{43}$. Así, quien activa el mecanismo de un arma de fuego expulsando un proyectil letal en dirección a otro individuo provocándole la muerte, mata, agrede, dispara, mueve un dedo, apunta, etc., todo ello a la vez, en términos que es posible sostener cada una de estas formas de acción, o todas a la vez, indistintamente. En dicho caso sería correcto afirmar una única acción, pero también varias, según del grado de abstracción aplicado y los significados que sean considerados relevantes. En segundo lugar, pues todo referente material se puede dividir o amplificar, o expandir y acotar hasta el infinito (por ejemplo, en torno a movimientos más amplios o más específicos y complejos), sin que, por sí mismo, pueda ofrecer elementos de juicio que ayuden a limitar dicha amplitud y relatividad ${ }^{44}$. Por ello no existen unidades de sentido que den cuenta de una clase o forma de acción o hecho en forma inequívoca, pues toda definición conceptual admite concreción en márgenes escasos o amplios de tiempo indistintamente (se puede matar con un disparo instantáneo o introduciendo pequeñas dosis de veneno durante semanas) ${ }^{45}$; ejecutarse en un reducido espacio o en amplias zonas de terreno (una bomba puede detonar en una pequeña habitación o afectar a una ciudad completa) o, inclusive, a distancia ${ }^{46}$. Por todo ello la dimensión empírica solo puede ser relevante una vez agotada la interpretación, en tanto aporta el sustrato que opera como reflejo de un acontecer espacio-temporalmente delimitado ${ }^{47}$, y que en este caso cuenta como realización (ejemplificación) de la (clase) de acción o hecho de que se trate ${ }^{48}$. Se debe por ello descartar (absolutamente) el uso de criterios materiales relativos a un determinado espacio, tiempo, contexto u "oportunidad" o al "carácter

\footnotetext{
40 Por todos, REYES (2016), p. 489.

${ }^{41}$ CUELLO (1979), p. 56. Lo intuitivo se confirma en un amplio uso, en doctrina y jurisprudencia, al margen de su reconocimiento formal (CUERDA (1997), p. 348). Para Cury, ni siquiera se somete a juicio, tanto en el concurso ideal como en la unidad natural de acción (CURY (2007), pp. 650, 651 y 663 y ss.). Lo propio en MEZGER (1955), p. 362.

42 STRATENWERTH (2005), p. 550; CARUSO (2018), pp. 25 y 26; MAÑALICH (2018a), p. 84. Por ello dicha constatación supone un proceso intensional relativo al significado de las cosas y su interpretación (MAÑALICH (2018c), p. 188; NOVOA (2005), T.II, p. 222; PALMA (2004), p. 112), a cuyo respecto lo empírico no juega ningún papel (VIVES (1981), p. 7; POSADA (2008), p. 80; FERNÁNDEZ (2013), pp. 39, 41, 42 y, especialmente, 44), en tanto pertenece al plano descriptivo y al contenido extensional de los tipos (OSSANDON (2018), pp. 966 y 967). Por ello es usual que junto al recurso naturalístico se recurra a criterios complementarios que, en definitiva, son los que definen, lo que ratifica su insuficiencia. MAURACH et al. (1995), pp. 523-525; CUERDA (1997), pp. 349 y 351.

${ }^{43}$ CARAMUTI (2018), p. 37; CUERDA (1997), pp. 346-347; ARCE (1996), p. 60.

${ }^{44}$ SUÁREZ (2001), p. 74; ARCE (1996), pp. 59-60; ESCUCHURI (2004), pp. 368 y 374; JESCHECK Y WEIGEND (2014), p. 1060. No se trata de una aproximación "difícil" de delimitar-como sugiere VAN WEEZEL (2021), pp. 314-315- sino que simplemente se trata de un criterio que carece de aptitud para poder hacerlo.

${ }^{45}$ El ejemplo se toma de NINO (1972), p. 37. En el mismo sentido ORTIZ Y ARÉVALO (2013), p. 317; CARUSO (2018), pp. 25-26; POLITOFF et al. (2003), p. 445.

${ }^{46}$ MAURACH et al. (1995), p. 569.

47 WELZEL (1993), p. 265.

${ }^{48} \mathrm{Al}$ respecto Véase MALDONADO (2020), p. 749. La idea de "realización" no es extraña en el derecho penal. Se utiliza mucho más de lo que parece, ya sea en torno al sustrato de un delito (FERNÁNDEZ (2013), pp. 36, 37 y 44), en casos de unidad de acción homogénea (MAÑALICH (2018a), p. 82, 94 y 95 y en MAÑALICH (2018c), p. 172 a 174) y en relación a los actos anteriores y posteriores copenados (NINO (1972), p. 61).
} 
ininterrumpido de una ejecución" ${ }^{49}$, pues su vaguedad e indeterminación ${ }^{50}$ solo favorece proposiciones fundadas en la mera arbitrariedad ${ }^{51}$.

\subsection{Aproximación normativista extrema o clásica. Unidad de hecho (o de acción) como unidad de delito}

Lo dicho lleva naturalmente a la consideración de criterios externos o normativos ${ }^{52}$, sea en relación a lo que cuenta como delito en el ordenamiento jurídico o en referencia a aquello que para el derecho ( $y$, en especial, para el derecho penal) puede representar una acción en términos genéricos, sin ningún tipo de especificación relativa a un tipo o clase en particular.

En cuanto a los primeros se ha sostenido por un importante grupo de autores que si la noción de acción o hecho se estructura en términos conceptuales el referente lo debe aportar el sentido del tipo, pues solo de esa forma la determinación coincide con aquellas clases o tipos de acción relevantes para el legislador penal ${ }^{53}$. Lo dicho equivale a sostener que constituirá un hecho o acción, a estos efectos, cualquier suceso que satisfaga una descripción típica; y que constituirán varios hechos los contextos en los que se puede afirmar la realización de varios tipos o delitos ${ }^{54}$. Bajo dichos supuestos también se hace plausible sostener que lo que cuenta como "hecho" es necesariamente más amplio que la noción de "acción" -en alusión directa al rol del resultado- pues no se podría hablar del mismo hecho si tras la explosión de una bomba se constata una pluralidad de víctimas, de conformidad con las exigencias típicas, pues en dichos casos, se debiesen sostener varios hechos y una misma acción (entendida en el sentido propio de la teoría del delito $)^{55}$.

A este respecto hemos ya advertido que dichas aproximaciones resultan inconciliables con el presupuesto que describe al concurso ideal de delitos toda vez que se hace virtualmente imposible llegar a sostener la concurrencia de una pluralidad de infracciones en "unidad de hecho" o de acción ${ }^{56}$. En efecto, si ambas definiciones (delito y hecho) son entendidas con base en un contenido equivalente (idéntico) ${ }^{57}$ se deberán afirmar tantos hechos o acciones como delitos concurran, de forma que la advertencia de un caso concursal siempre adoptará la forma de una "pluralidad de hechos" ${ }^{58}$, sean homogéneos o heterogéneos ${ }^{59}$. Lo dicho también pone en evidencia que el criterio resulta completamente inútil para sostener un tratamiento penológico diferenciado pues, por sobre lo dicho, no permite tomar en cuenta ningún factor diferencial que sea adicional a las propiedades que ofrecen las respectivas infracciones constatadas. Así, se refuerza la idea de que tres muertes ocasionadas por la detonación de un

49 POLITOFF et al. (2003), p. 445; WESSELS et al. (2018), p. 540; NOVOA (2005), pp. 222 y 223 . Aplica también a la identificación de una "interrupción relevante" (ROXIN (1997) p. 947).

50 NOVOA (2005), p. 222; FRISTER (2016), p. 674.

51 MAURACH et al. (1995), p. 523; CUERDA (1997), pp. 349 y ss. (en torno a la jurisprudencia española); ARCE (1996), p. 60; Asimismo GARCÍA (1995), p. 347 (Binding asume un complemento en base a "intuición").

52 Referidos a una orientación "constructivista”, SILVA (2003), pp. 44 y 50.

53 Por todos, MIR (2005), pp. 625-626. En un sentido equivalente se pronuncia POLITOFF et al. (2003), p. 445.

${ }^{54}$ MIR (2005), p. 626.

${ }^{55}$ En este sentido MIR (2005), pp. 626-627; CID (1994), p. 50; ROIG (2011), pp. 136-137 (con cita de autores de referencia). En estos casos lo relevante no es el resultado, sino su consideración en el tipo (en cuanto descripción).

${ }^{56}$ Muy preciso MAÑALICH (2018a), pp. 83-84; REYES (2016), pp. 493-494.

${ }^{57}$ SANZ (1986), p. 148.

58 Lo dicho lleva todos los casos discutibles a extremos, pues obliga a considerar una pluralidad en cada suceso que cuente como realización formal del tipo, como sucede con buena parte de los casos de unidad natural o jurídica de acción (ejecución sucesiva, iterativa y sucesos reiterativos homogéneos en general). Por ello, no es extraño que los partidarios de esta doctrina recurran en dichos supuestos a criterios complementarios, incluso a algunos de corte empírico o naturales. Así, CARAMUTI (2018), p. 79 y en MIR (2005), pp. 625 y 628; GARRIDO (2007), p. 350. Lo constata CARUSO (2018), p. 28.

${ }^{59}$ La aclaración es necesaria a pesar de que en el texto parece irrelevante. Ello es así por el simple hecho de que la tesis expuesta se suele sostener respecto de casos de delitos homogéneos (de la misma clase) de carácter doloso, sin advertir que lo dicho se sostiene en igual medida respecto de todos los demás (es decir, de los configurados en torno a un concurso heterogéneo) en los que se plantee la necesidad de problematizar una "unidad de hecho". En el mismo sentido, muy preciso, MAÑALICH (2018a), p. 87. Se puede corroborar lo dicho en MIR (2005), p. 633 y, en Chile, en GARRIDO (2007), pp. 338 (muy nítido), 348 y 349 . Esta inconsistencia hace pensar que las auténticas razones de la interpretación son otras. Sobre los diversos planteamientos véase ROIG (2011), pp. 142-148 y 158 y ss.; en contra, con buenas razones, véase MAÑALICH (2018 a), pp. 88 y 89; BUSTOS (1962), pp. 90 y ss. 
mismo artefacto explosivo reflejan un desvalor completamente equivalente al caso en que los mismos tres resultados se producen con base en diversos disparos de un arma de fuego, ejecutados en tiempos, contexto y lugares diversos. Con ello, la posibilidad de recurrir a un criterio externo o normativo pasa por el uso de una conceptualización diversa sobre lo que debe entenderse como un hecho o acción, correspondiente al segundo grupo de propuestas antes aludido, entre las que destaca el recurso al (mismo o único) "resultado" o a la misma (y única) finalidad ${ }^{60}$.

\subsection{Aproximación normativista. La unidad de hecho o acción basada en criterios auténticamente "externos"}

Para algunos se puede identificar un hecho o una acción cada vez que la intervención humana provoca un cambio en la realidad ${ }^{61}$, de forma que puede identificarse la unidad de acciones o hechos o su pluralidad acorde a los efectos constatables ${ }^{62}$. Dicha modificación tangible no puede en todo caso ser solo equivalente a "algo que ha sucedido" (cualquier "cosa que sucede", en los términos del Diccionario de la Real Academia Española de la lengua). Debe corresponder como mínimo a un hacer, esto es, a algo que ha sido "producido" o "provocado" 63. Pero además a algo que ofrezca propiedades o elementos de juicio relevantes para habilitar a la emisión de una (des)valoración jurídica en particular ${ }^{64}$, asociada a significados idóneos para adoptar una decisión sobre pena. No hay que olvidar que el sentido de la unidad de hecho en este contexto apunta precisamente a motivar una regla penológica que sustituya a aquellas que han sido previstas para cada delito en la parte especial, de forma que lo que cuenta como hecho debe ofrecer un componente diferencial e idóneo a dichos efectos ${ }^{65}$. Se debe por ello descartar toda noción que carezca de una dimensión de sentido como la referida, como sucede con esta alusión al "efecto" o resultado ${ }^{66}$. Por sobre ello, debe corresponder además a una instancia de carácter unitario en la que se puedan identificar dos acontecimientos diversos (en este caso, delitos), lo que en términos sencillos supone un determinado nexo o vínculo que se construya al margen de los contenidos propios de las unidades concurrentes (auténticamente externo a aquellas). Esta condición tampoco se satisface tras la sola referencia a la constatación de un

\footnotetext{
${ }^{60}$ Vale la pena poner de relieve que estos criterios se suelen calificar como empíricos, pues su carácter genérico (aplicable a cualquier clase de "acción" o "hecho") induce a pensar que son expresiones más cercanas a la realidad (NOVOA (2005), p. 222). De ahí que se traten como acciones "en sentido natural". No obstante, lo que vale como acción en dichas perspectivas también depende de una conceptualización (ROIG (2011), pp. 86 y ss.) en cuanto modificaciones de la realidad (perceptibles) que presentan una dimensión de sentido. Su identificación es por ello normativa. Sobre esta base se reserva normalmente el calificativo "jurídico" para las propuestas que asimilan acción o hecho y "delito", con resultados equívocos. Las falencias de dicha tesis hacen suponer que todo depende de una aproximación naturalística; cuyas debilidades congénitas (CARUSO (2018), p. 24; JOSHI (1992), pp. 613-614) dejan la impresión de que no hay más remedio que prescindir de la propia categorización (MAÑALICH (2005), pp. 1036-1037; ROIG (2011), p. 356; VIVES (1981), p. 42; GUINARTE (1988-1989), p. 206) sin advertir que existen alternativas diversas (intermedias). A dicho respecto es correcto sostener que las aproximaciones o son naturalísticas (físicas) o son jurídicas (normativas) (MUÑOZ (1986), p. 359 en Chile o MIR (2005), p. 625 y ROIG (2011), p. 22 en España) pero no el suponer que cada perspectiva se expresa en un solo tipo o clase de criterio. En ambos casos las opciones son variadas.

${ }^{61}$ VAN WEEZEL (2021), pp. 312-318.

${ }^{62}$ En este sentido efecto no es igual a resultado, pues se refiere a una noción más amplia. Al respecto, con claridad, VAN WEEZEL (2021), pp. 316-318, quien ejemplifica -entre otros- con el cambio perceptible tras una afirmación injuriosa.

${ }^{63}$ Ello supone una modificación en la realidad (un efecto o resultado) que se afirma a partir del contraste de un estado de las cosas con la situación precedente a aquello que se pretende que cuente como tal. VÁSQUEZ (1996), p. 220.

${ }^{64}$ A nivel general, véase VAN WEEZEL (2021), pp. 314 y ss. Lo dicho explica por qué resulta insuficiente la sola referencia a efectos o resultados (supondría valorar "movimientos o enervaciones musculares, como indica ZAFFARONI et al. (2002), p. 857), por sobre los problemas propios de su indeterminación como parámetro (similares a los de los criterios naturalísticos) que demanda a fin de cuentas un criterio de selección adicional. Así, NOVOA (2005), p. 232; POSADA (2008), pp. 81 y 82; Lo propio se replica con las referencias a la lesión; al bien jurídico (sobre los orígenes del criterio véase MATUS (2000), pp. 10 y 23) o a su carácter personalísimo (WESSELS et al. (2018), p. 542; FRISTER (2016), p. 690; ESCUCHURI (2004), pp. 390 y 391; POSADA (2008), p. 82; CÁRDENAS (1973), p. 36; GARRIDO (2007), p. 337; CURY (2007), p. 651; POLITOFF et al. (2003), p. 449.

65 Por ello, como sostiene VAN WEEZEL (2021), p. 310, la unidad de hecho concursal no puede ser equivalente a la unidad de acción típica, asumiendo dos diferencias que considera fundamentales: el concepto debe ser más amplio o comprensivo y que es extensional. Asimismo, JAKOBS (1997), pp. 1074 y 1075 a favor de una noción "pre típica” y diversa lo que cuenta como delito.

${ }^{66}$ MALDONADO (2020), p. 748. En el sentido objetado, parcialmente, MAÑALICH (2018a), pp. 83-84 (en cuando lo refiere a una definición “débilmente extensional”). Asimismo, REYES (2016), pp. 493-494.
} 
efecto o resultado provocado o producido pues no aporta en algo diverso a lo que se considere relevante para la respectiva pluralidad de delitos.

Entre los demás criterios destaca en doctrina el recurso a la finalidad o motivación unitaria, el llamado test de evitabilidad conjunta y el ya mencionado vínculo de necesidad o indivisibilidad de la ejecución de las diversas realizaciones delictivas, de cuyos contenidos nos pasamos a ocupar. La finalidad única (muy influyente en el siglo XIX y hasta la mitad del XX) ${ }^{67}$ postula la posibilidad de afirmar una unidad cada vez que un delito se ejecuta para posibilitar la comisión de otro, pues se trataría de un único conjunto que responde a una motivación única ${ }^{68}$. Así sucedería, por ejemplo, con quien falsifica para estafar ${ }^{69}$. No obstante, esta propuesta pasa por alto que se puede y debe identificar una finalidad independiente en torno a cada ilícito, de forma que en el respectivo proceso de atribución se podrán constatar, afirmar y valorar tantas finalidades o motivaciones específicas como delitos concurrentes. Y no solo una unidad ${ }^{70}$. En el ejemplo, se podrá constatar la finalidad de falsificar y además la de defraudar, debiendo ambas ser consideradas y valoradas en su especificidad, sin que exista una razón que habilite a obviar o minusvalorar la consideración de alguna de ellas.

Por su parte, la idea de funcionalizar algunas de esas finalidades (preferentes) en favor de otras pareciera más fructífera, pues hace operar a estas últimas como un motivo o razón única y última de todos los delitos, en términos que es más sencillo identificar o sostener una "única decisión de delinquir" en el conjunto de todos los delitos. En el ejemplo citado, lleva al interprete a asumir que la decisión de falsificar solo se explica por la de estafar, de forma que resulta plausible entender que el infractor no habría incurrido en la falsedad de no ser por la decisión de defraudar. Tras dicho supuesto la única finalidad relevante pasaría ser la "principal", cuya consideración se estimaría concurrente en los demás ilícitos en el plano de la motivación (que incide en la finalidad concreta y específica de llevarlos a cabo) ${ }^{71}$.

A dicho respecto resulta relevante tener en cuenta que dicha lectura propone un sustrato equivalente a una conexión de carácter instrumental, en tanto se trata de entender que una parte de los ilícitos es meramente funcional a la ejecución de otro u otros, que por ello pasa a ser definido como el único que "realmente" se desea en forma principal o "final"72. Con ello la tesis se torna altamente problemática pues propone una comprensión del supuesto propio del concurso ideal que sería idéntica a la del concurso medial, hipótesis que se encuentra descrita y tratada expresamente en la ley en forma independiente $y$, además, en paralelo al concurso ideal ${ }^{73}$. Así, sería absurdo que el legislador se haya ocupado de regular el mismo supuesto (idéntico) a través de dos reglas diferentes, particularmente si en ambas se hace con el objeto de aplicar los mismos efectos. Por ello, y en tanto es claro que dicho supuesto se encuentra tratado en la regla adscrita al llamado concurso medial, habría que concluir que el supuesto del concurso ideal debe corresponder a algo diferente.

Pero aún más, también es relevante tener en cuenta que incluso en el campo del concurso medial dicho dato resulta insuficiente como factor o criterio de unificación, al menos en la perspectiva que ofrece el legislador. Ello es así, pues el tenor literal de la respectiva regla exige en forma adicional que el vínculo medial de que se trate se pueda calificar como "necesario",

\footnotetext{
${ }^{67}$ ALVAREZ (2008), p. 66.

${ }^{68}$ Así en WESSELS et al. (2018), pp. 536 y 540; STRATENWERTH (2005), p. 537; ESCUCHURI (2004), p. 370; ARCE (1996), p. 45: RIGHI Y FERNÁNDEZ (2005), p. 329 y, en nuestro medio, ETCHEBERRY (1964), p. 100; ORTIZ Y ARÉVALO (2013), pp. $317-318$ (si bien asumen que junto a la voluntad también son determinantes los demás elementos del tipo); GARRIDO (2007), p. 337. Cita de otros autores de referencia en SUÁREZ (2001), p. 76. Constituye un criterio de uso preferente en USA y Puerto Rico, si bien se acepta con matices relevantes (véase, al respecto, VÁSQUEZ (1996), pp. 218-219).

${ }^{69}$ Así, por ejemplo, ETCHEBERRY (1964), p. 100.

70 Por todos, VÁSQUEZ (1996), pp. 219-220.

71 Por todos, ARCE (1996), pp. 53 y ss. Cabe puntualizar a este respecto que el delito "fin" no tiene por qué ser el último en términos cronológicos, como sucede en la "conexión consecuencial”. Véase FONTECILLA (1956), p. 74. El tema es sin embargo controvertido. En este sentido véase GUINARTE (1988-1989), pp. 173-174; ORTIZ Y ARÉVALO (2013), p. 342.

72 VAN WEEZEL (2021), pp. 314-316; ARCE (1996), pp. 53 y ss. Implícito en MAÑALICH (2005), p. 1039; FONTECILLA (1956), p. 72; SANZ (2012), p. 63; JOSHI (1992), pp. 634 y 635.

${ }^{73}$ Art. 75 inciso primero del Código penal chileno: "La disposición del artículo anterior no es aplicable en el caso de que un solo hecho constituya dos o más delitos, o cuando uno de ellos sea el medio necesario para cometer el otro" (el destacado es nuestro).
} 
decisión que además encuentra respaldo material en buena parte de la doctrina en la actualidad $^{74}$. Con ello, se debe concluir que es dicho carácter el que habilitaría a identificar o sostener un tipo o forma de unidad idónea para justificar el efecto penológico previsto, pues parece claro que la sola disposición voluntaria o contingente de algunos delitos al servicio de otros no es considerada suficiente a dichos efectos. Así, parece difícil discutir que lo determinante radica en el carácter inevitable de la concurrencia conjunta (en ese sentido, "necesaria") en términos que el conjunto de delitos se muestre como un todo indivisible para la voluntad del ejecutor. Desde esta perspectiva todo parece indicar que la razón del privilegio se asocia al hecho de que la ejecución del conjunto se deja apreciar como una especie de "imposición" para el ejecutor, quien se encontraría frente a la disyuntiva de aceptar la ejecución completa como un todo o rechazarla en los mismos términos, apreciación o "condicionante" que disminuiría la entidad del reproche asociado a su comisión. Se trataría por ello de un caso de "menor culpabilidad" 75 .

Se podrá advertir que esta acotación no descarta que la conexión "motivacional" descrita pueda ofrecer un auténtico sentido unificador, pues parece efectivo el que se pueda llegar a interpretar el conjunto así descrito como uno que se configura en base a partes o fragmentos de una misma y única ejecución (al margen de su propia individualidad). Lo relevante radica en advertir que el propio legislador pareciera considerarlo insuficiente como razón explicativa o justificación del régimen penológico propuesto ${ }^{76}$. A nuestro juicio dicho criterio se confirma si tenemos en cuenta que es bastante difícil aceptar la idea de que se puede valorar una motivación consistente ni más ni menos que en delinquir, y menos aún si con ello se procura fundar una atenuación o privilegio. En su caso, constituiría más bien un motivo que, de ser valorado $^{77}$, aportaría razones para sostener un tratamiento penológico más riguroso, como sucede paradigmáticamente en el tratamiento que el legislador concede al llamado "robo con homicidio" y en el supuesto básico del robo violento o de la violación (en cuanto al papel funcional que en dichos casos cumple la coacción) ${ }^{78}$.

Todo lo dicho lleva a que un sector importante de la doctrina postule que la exigencia complementaria o adicional prevista para la relación medial (el carácter necesario o indivisible de la ejecución conjunta) debe también caracterizar al supuesto de unidad que se regula en el concurso ideal. De esta forma no solo se lograría corregir su amplitud e indeterminación inicial (asociada en la generalidad de los casos a una noción "naturalística" referida a la mera simultaneidad), sino que además se la dotaría de una razón idónea a los efectos requeridos.

Lo dicho resulta particularmente relevante pues da cuenta de la principal razón que nos lleva a disentir del criterio propuesto. En concreto: si en el concurso medial se exige, formal y expresamente, que los delitos concurrentes tengan una vinculación "necesaria" (o si se quiere, que sean indivisibles), no parecen existir razones para extender dicha exigencia formal a un caso que no la contempla, teniendo en cuenta que no aparece en modo alguno mencionado en la descripción del concurso ideal y que además ambas regulaciones se encuentran establecidas en la misma (idéntica) disposición. Así, todo indica que en este último caso la sola constatación de una unidad de hecho o de acción debe ofrecer un contenido que por sí mismo resulte suficiente para justificar el efecto previsto por el legislador, sin que sea necesario recurrir a criterios o contenidos complementarios o adicionales a los mencionados formal y expresamente en la ley.

Frente a ello, algunos de los partidarios de esta tesis se han ocupado de precisar que el carácter necesario o inevitable que se puede predicar de un conjunto de delitos constituye precisamente la razón que habilita a sostener una unidad de hecho, de forma que su efecto

\footnotetext{
${ }^{74}$ Históricamente (Siglo XIX) primó la idea de que a nivel material bastaba la conexión medial para unificar el hecho. Al respecto GUINARTE (1988-1989), p. 159; CALDERÓN (1995), p. 152.

75 Por todos, ORTIZ Y ARÉVALO (2013), p. 343; y NÚÑEZ (1986), pp. 19-20.

${ }^{76}$ En ese sentido, concretamente, MAURACH et al. (1995), p. 582

77 Sobre la posibilidad de valorar las motivaciones, en la medida que admitan un juicio de atribución, COUSO (2006), pp. 552 y ss.

${ }^{78}$ En este sentido el Código Penal español de 1848 consideraba a la conexión medial como una circunstancia agravante (art 10 № 11 ) lo que siempre sirvió para ratificar que el privilegio del concurso medial se asocia a lo indivisible de los delitos concurrentes. Al respecto SANZ (1986), p. 179. En relación a los delitos “complejos" citados véase GARRIDO (2007), tomo IV, pp. 198 y ss.; ETCHEBERRY (1997), tomo III, 338 y ss.
} 
propio incidiría sobre un contenido reglado (formal y expresamente). De ser así, no constituiría un criterio ajeno, externo o adicional al que se propone para definir el supuesto propio del concurso ideal, sino que aportaría el contenido preciso que permite delimitar la unidad de hecho o acción ${ }^{79}$. Tendría además la ventaja de proponer una razón o fundamento idóneo para reclamar un tratamiento penológico privilegiado (como en el concurso medial), en tanto el carácter indivisible de los delitos permitiría -según ya hemos visto- sostener un menor reproche o una menor culpabilidad ${ }^{80}$.

Dicho esto, creemos que en este caso tampoco se puede desconocer el mérito unificador que ofrece el planteamiento recién descrito. No obstante, también creemos que resulta discutible su virtualidad fundante de un efecto privilegiante. Hay que tener en cuenta que quien resuelve la ejecución de un hecho que supone la comisión de un conjunto de delitos adopta decisiones respecto a todos y cada una de ellos, siendo irrelevante el que su ejecución se presente en términos alternativos o como un todo indivisible. Así, quien resuelve dar muerte a una mujer embarazada, conociendo dicho estado y provocando dicho resultado en conjunto con la muerte del feto, se hace acreedor del juicio de (de)mérito que corresponde al homicidio y al aborto en términos íntegros, sin que a dicho respecto se pueda considerar que su pretensión auténtica, profunda u original sólo se haya estructurado en torno al primero de esos delitos en particular. El carácter necesario o indivisible de los delitos no hace más que configurar la opción de delinquir en términos más complejos (pragmáticos), pues no parece discutible que ofrece al infractor la disyuntiva de acometer el conjunto (todos y cada uno de ellos) o abstenerse del total $^{81}$. Lo relevante es que nadie podría negar que ambas opciones son tales (esto es, alternativas evitables), ni que, en los casos de ejecución "global" el infractor no haya resuelto la ejecución de la totalidad de las infracciones comprometidas. Demanda por ello, la totalidad del respectivo reproche de culpabilidad.

Lo dicho se corrobora en la defensa que se sostiene en Chile del criterio de la evitabilidad conjunta, cuyo contenido resulta del todo equivalente al que aquí se analiza ${ }^{82}$. En dicho caso, además, se postula el carácter indivisible de un conjunto de delitos solo a los efectos de sostener una unidad (de acción o de hecho) reconociendo que no aporta un contenido idóneo para modificar los términos de la atribución ${ }^{83}$.

Por sobre ello hay que tener en cuenta dos consideraciones adicionales determinantes. Primero, que se trata de un criterio que opera en un plano descriptivo o extensional, que por ello resulta ajeno a la significación valorativa que supone su utilización en el campo de la determinación de la pena ${ }^{84}$. Y además, que la utilidad que puede brindar a los efectos de la consideración de una determinada clase de unidad entre dos ilícitos -que ya hemos dicho que es efectiva- resulta incompatible con la afirmación de un concurso de delitos acorde a los usos tradicionales y dominantes ${ }^{85}$. Ello es asi, pues la constatación de una auténtica relación de "necesidad" o indivisibilidad habilita a sostener que el contenido de desvalor respectivo "se encuentra incluido o considerado en el otro" (conforme se sostiene acorde a la terminología

\footnotetext{
${ }^{79}$ Avala dicha tesis el hecho de que la doctrina dominante entienda que el concurso medial se construye a partir de casos de concurso real que, por definición, se ejecutan "en pluralidad de hechos" (sobre ello véase BUSTOS (1962), pp. 79-80; FONTECILLA (1956), p. 72; ORTIZ Y ARÉVALO (2013), p. 334; POLITOFF et al. (2003), p. 444. CALDERÓN (1995), pp. 146, 152 y 153.). Así, se favorece la idea de que la exigencia de la conexión "unificadora" (en cuanto (indivisible) está presente en la base de la afirmación de una unidad de ejecución, de forma que por esta razón debe ser construida, adicional y artificialmente, en los casos de concurso medial. Así, se explica que este mismo elemento -que sería común a ambos supuestos- solo se haya expresado formalmente en relación al caso del concurso medial, pues en los demás (los propios del concurso ideal) estaría reflejado precisamente tras la afirmación de la unidad de hecho.

${ }^{80}$ MUÑOZ (1986), p. 360; CÁRDENAS (1973), pp. 79-80.

${ }^{81} \mathrm{El}$ mismo razonamiento se replica en torno a los casos que se tratan bajo el rótulo del llamado dolo de las consecuencias necesarias o seguras, a cuyo respecto la doctrina uniformemente acepta la atribución completa (a título de dolo). Sobre ello, por todos, CURY (2007), pp. 316-317.

${ }^{82} \mathrm{Al}$ respecto véase MAÑALICH (2018c), p. 188; MAÑALICH (2018a), p. 85, con base en la propuesta de Kindhauser. Crítica en MAURACH et al. (1995), p. 528.

${ }^{83}$ Así se reconoce por MAÑALICH (2018a), p. 85. A fin de cuentas el criterio no hace más que extender a este campo la conceptualización propia de lo que cuenta como una acción como base para su atribución, aportando, en igual sentido y medida, a la determinación del contexto unitario que cuenta como supuesto del concurso ideal.

${ }^{84} \mathrm{Al}$ respecto véase MAURACH et al. (1995), p. 528; VAN WEEZEL (2021), pp. 310-311.

85 Por todos, MIR (2005), p. 634; MAÑALICH (2005), p. 1199 y MAÑALICH (2004), pp. 505-506.
} 
tradicional) ${ }^{86}$, tal como se propone y concluye -desde siempre- en el campo del concurso aparente de leyes penales, donde resulta prácticamente unánime la afirmación de la "consunción" ${ }^{87}$. De ahí que la doctrina que defiende este criterio se vea obligada a sostener dicha relación con una valoración "en concreto", esto es, acorde a las circunstancias, que muchas veces se termina ubicando -casi literalmente- bajo condiciones que desnaturalizan la calificación, pues se ubican en un plano "intermedio" y más próximo a la disposición voluntaria ${ }^{88}$. Si bien dicha forma o clase de relación puede resultar atendible a los efectos indicados, ello solo es posible si se adopta un tipo de aproximación en particular, donde lo "concreto" alude al "estado en que se le presentan las cosas", lo que es propio de un plano pragmático o meramente descriptivo ${ }^{89}$.

\subsection{Valoración de conjunto y aproximación histórica}

Lo dicho hasta el momento evidencia que los planteamientos conocidos procuran identificar razones asociadas a lo injusto o a la culpabilidad ${ }^{90}$, lo que los ata a fin de cuentas a contenidos relativos a lo que son los delitos en sí (a los presupuestos de la imputación) y no a auténticas condicionantes externas que sirvan para sostener cuándo o cómo se puede afirmar que se presentan en "unidad de hecho". Así se explica que, más allá de la primera apariencia, y de que en todos los casos logren aportar aproximaciones idóneas para identificar una unidad en torno al conjunto de delitos concurrentes, no logren a fin de cuentas proponer un significado valorativo autónomo, diferencial o adicional al que se extrae de aquellos. Así sucede con el sentido unificador que se propone tras el recurso a una manifestación de voluntad, a la valoración de un motivo que los conecte (en torno a una misma finalidad), a la cantidad de efectos provocados o a su carácter evitable. De ahí que este estado de desarrollo no pueda ser calificado como satisfactorio y torne plausible la idea casi dominante en doctrina que aboga por el abandono de la categoría (unidad de hecho) y de la diferenciación (concurso real e ideal de delitos). La unidad de hecho en el concurso ideal constituiría por ello una consideración equívoca, expresiva de una reminiscencia histórica. Así sólo parece posible explicar su existencia, pero no justificarla.

No obstante, una aproximación más detallada de la perspectiva histórica parece aportar concretas luces a este último respecto, contra la opinión más difundida. En materia concursal la distinción originaria más relevante se constata en Roma en torno a la naturaleza de las infracciones ejecutadas, diferenciando el concurso homogéneo del heterogéneo ${ }^{91}$. La necesidad de ofrecer una distinción encuentra en este caso su origen en una cuestión pragmática de naturaleza procedimental, asociada al hecho de que no siempre la autoridad encargada de imponer las condenas previstas era la misma. En concreto, la regla general para los casos de pluralidad de infracciones consistía en aplicar una única sanción, normalmente, la más gravosa, pero en la práctica dicha regla solo se podía aplicar como régimen en torno a los ilícitos que se

\footnotetext{
${ }^{86}$ A dichos efectos se recurre de preferencia al principio de consunción (ETCHEBERRY (1997), pp. 124-125; NOVOA (2005), p. 255; GARCÍA (1995), pp. 384 y 385; MALDONADO (2013), p. 202) especialmente fundado en la consideración de que la ejecución de un delito resulta "inherente" a la del otro (MAÑALICH (2005), pp. 1051 y ss.; ETCHEBERRY (1997), p. 125). Así, parece claro que no es posible ejecutar un homicidio sin llevar a cabo lesiones (en sentido "típico") pues, a fin de cuentas, se trata de una concurrencia inevitable. ${ }^{87}$ ETCHEBERRY (1997), pp. 124-125; NOVOA (2005), pp. 231, 234 y 235; GARCíA (1995), pp. 384-385. Especial relevancia tienen los casos asociados a la idea de "inherencia”. MAÑALICH (2005), pp. 1051 y ss.; ETCHEBERRY (1997), p. 125).

${ }^{88}$ Lo relevante es que también se puede arribar a la conclusión de que se debe descartar el concurso en una aproximación "en concreto" en tanto responda a la consideración de las propiedades presentes en los respectivos tipos de delito concurrentes. El tema se discute, especialmente en torno a nociones como la "regularidad". Al respecto véase ARTAZA (2021), pp. 105 y ss.; BUSTOS (1962), p. 74; ETCHEBERRY (1964), pp. 51, 53 y 127; MATUS (2000), p. 37; CARAMUTI, (2013), pp. 47-60; NOVOA (2005), p. 255. Las críticas se asocian a indeterminación (CID (1994), p. 46) y por cuanto se sostiene que la mera tendencia estadística no es idónea a los efectos que se señalan (GARCÍA (1995), pp. 177, 388 y 400).

89 MAÑALICH (2004), p. 506. ORTIZ Y ARÉVALO (2013), p. 343; POLITOFF et al. (2003), p. 444. Sobre la caracterización de la valoración como abstracta o concreta a este respecto véase GUINARTE (1988-1989), pp. 189-190.

${ }^{90}$ En torno a este objetivo véase VAN WEEZEL (2021), pp. 308-309 y 312.

${ }^{91}$ A nuestro juicio se trata precisamente (hasta hoy en día) de la distinción fundamental en toda la teoría concursal. En el mismo sentido, MAÑALICH (2018c), p. 172; MAÑALICH (2005), p. 1141; JESCHECK Y WEIGEND (2014), p. 1059, nota 5 (citada como doctrina minoritaria).
} 
encontraren consagrados en un mismo estatuto ${ }^{92}$. En los demás casos, dicha dinámica se complejiza por el hecho de que las autoridades competentes para imponer las sanciones eran distintas, de forma que no queda más opción que imponer un régimen que en la práctica era acumulativo $^{93}$. De esta forma, la pluralidad de sanciones no aparece originalmente vinculada a una pluralidad de fundamentos incriminatorios (estatutos, normas) o delitos concurrentes, sino a una cuestión meramente pragmática o contingente asociada a la competencia funcionaria. Por ello no es extraño que los problemas concursales originales aparezcan vinculados en exclusiva al concurso de penas que resultan ilusorias o antinómicas ${ }^{94}$.

Se pueden constatar más adelante algunos casos (específicos) de sanción acumulativa impuestos ante el mismo magistrado, si bien no obedecen a criterios uniformes o claros $^{95}$, sin que por ello se llegue a sustituir el criterio de pena única -por el conjunto- como regla de base o general ${ }^{96}$. Se constata no solo en Roma, sino también en el derecho canónico y hasta la baja edad media, donde -recién- empieza a cobrar sentido la consideración de un régimen acumulativo. Lo relevante es que también en dicha época comienza a tomar sentido la distinción entre unidad y pluralidad de hecho o acción -como distinción relevante- si bien con base en consideraciones del todo diversas ${ }^{97}$. El que su asentamiento haya cobrado importancia en forma posterior y que haya tenido lugar en forma paralela a la consolidación del llamado "principio de la acumulación" ${ }^{98}$, motivó a fin de cuentas una virtual confusión en la literatura, según pasamos a revisar.

Ambas distinciones encuentran sus orígenes en los prácticos italianos, de donde pasan a Koch (1783), sindicado como el padre de la "moderna teoría concursal" (centrada en la distinción entre unidad y pluralidad de ejecución ${ }^{99}$. Toma fuerza la idea de que se debe reconocer que los casos de unidad de hecho ameritan una agravación si expresan una pluralidad delictiva (al menos en delitos graves) ${ }^{100}$, régimen que contrasta con el asignado a los casos de reiteración que es donde se ubica lo que hoy en día conocemos como concurso real. En relación a estos últimos (cualquiera, incluyendo al concurso real) se generaliza el tratamiento (originalmente tópico) consistente en la aplicación de drásticas sanciones, cualitativamente más aflictivas, particularmente en situaciones de homogeneidad (vinculadas a profesionalización o

\footnotetext{
92 En estos casos (delitos homogéneos, del mismo tipo, clase o título) se consideraba que la pluralidad de casos no era tan relevante pues a fin de cuentas se trataba del mismo "tipo" de vulneración o quebrantamiento. Al respecto, véase FERRINI (2017), pp. 135-138. En ello la unidad de fundamento es equivalente a la de bien jurídico, en tanto asociada al título. Al respecto ALVAREZ (2008), pp. 42-45. ${ }^{93}$ En dicha época era usual que la autoridad encargada de los castigos fuese diversa según la materia, de forma que la acumulación se presenta como el "único tratamiento posible". FERRINI (2017), pp. 135-138.

${ }_{94}^{4}$ SANZ (1986), pp. 39 y 48; MEZGER (1958), p. 330 (en relación a Roma), quienes radican el origen de la teoría concursal en perspectivas jurídico-procesales.

${ }^{95}$ Con referencias al derecho romano, véase SANZ (1986), p. 41 y, el mismo (en pp. 42 y 43 ) en relación al derecho germánico. En el mismo sentido FERRINI (2017), pp. 135 y 138 (con una variedad de ejemplos).

${ }^{96}$ En la actualidad la costumbre tiende a favorecer la idea de que el régimen de acumulación de sanciones debiese ser la mecánica natural y, por ello, se asume que opera (o debiese operar) “por defecto" (GARCíA Alberó (1995), p. 223). Dicha apreciación es correcta, pero solo si se la comprende bajo condiciones que habilitan a la simultaneidad. La acumulación sucesiva -no simultánea- no goza de dicho privilegio, más allá de que bajo las costumbres imperantes parezca intuitiva (si bien tosca, formal y, por momentos, "primitiva", como sostiene MUÑOZ (1986), p. 344). Por un lado, dicho proceder desnaturaliza las decisiones legislativas (DE DOU (1800), p. 140) pues el resultado acumulativo parece contrariar el contenido, significado o sentido de reglas que se resuelven para casos de ejecución individual (DE LA RUA (2013), p. 16; CUERDA (1992), p. 36-37). Además, modifica el propio contenido de aflictividad que suponen las condenas (SANZ (1986), pp. 25-26; GÓMEZ DE LA SERNA Y MONTALBÁN (1851), p. 144; CARAMUTI (2018), p. 306; ZAFFARONI et al. (2002), p. 852) y pone en riesgo la satisfacción de la idea de proporcionalidad, pues se puede terminar castigando más severamente un hurto reiterado que un homicidio como destaca acertadamente (CUERDA (1992), p. 94). Lo más relevante, sin embargo, apunta a la inmediatez de la sanción, por la indiscutible pérdida de sentido que supone una postergación en el tiempo (en especial si se pretenden efectos preventivos diversos de la mera contención). Por último, la valoración que supone el acto de adjudicación de condena suele desvanecerse si primero se fijan las penas y luego se procede, simple y mecánicamente, a sumar los resultados, pues el conjunto final (y el propio proceso recién descrito) carecería por completo de una dimensión de sentido como tal. De ahí que la tendencia histórica haya favorecido una resolución reflexiva, completa y motivada, desarrollada a través de un proceso de valoración (único y) unificado.

${ }_{97}$ Al respecto véase ALVAREZ (2008), pp. 35-36; SANZ (1986), p. 42 y, en relación al derecho canónico, en p. 43. También se advierten algunas opiniones en contra de estas afirmaciones, en especial, en torno al derecho romano. Al respecto véase, por todos, CÁRDENAS (1973), p. 11.

${ }^{98}$ SANZ (1986), p. 48. FONTECILLA (1956), p. 78.

${ }^{99}$ CÁRDENAS (1973), pp. 11 y 12; ARCE (1996), p. 35; ESCUCHURI (2004), p. 207; SANZ (1986), pp. 39 y ss., MEZGER (1958), p. 331.

${ }^{100}$ CÁRDENAS (1973), pp. 11-12. Lo que se plantea coincide con la función de clarificación que posteriormente se le atribuye en contraste con el concurso aparente de leyes penales. Sobre ello STRATENWERTH (2005), p. 552; JESCHECK Y WEIGEND (2014), p. 1073.
} 
contumacia $)^{101}$. Este desarrollo culmina en Feuerbach - pasando previamente por Becker ${ }^{102}$ quien en definitiva asocia este desarrollo, y la distinción, con el principio de la acumulación (propio del concurso real) ${ }^{103}$, bajo la premisa de que cada delito debe recibir su propia sanción ("qua delicta tot poneae") ${ }^{104}$, considerado hasta el momento como un régimen más bien "excepcional" o especialmente aflictivo, en relación al sistema común o de base (centrado en la absorción o unificación agravada). Pero además, se trata de un desarrollo que pone de relieve que el sentido que une pluralidad y pena en dicho contexto no está referido a la noción de delito (ni a los delitos cometidos), por la sencilla razón de que en los casos concursales de unidad de ejecución (concurso ideal) también se advierte la misma pluralidad de infracciones ${ }^{105}$. Así, queda claro que la pretensión de que "cada delito reciba una pena" (en sentido literal) también sería aplicable a la ejecución concursal en unidad de hecho (pues también da cuenta de varias infracciones), de forma que la distinción no resulta en modo alguno relevante para la consideración de un régimen acumulativo ${ }^{106}$.

Así, la asociación entre concurso real y régimen de acumulación solo se explica en atención a que se trata de un caso de reiteración delictiva ${ }^{107}$, en el que cada manifestación contraria a derecho es valorada como un acto de rebeldía independiente, que reclama por esa razón su correspondiente sanción y el conjunto de las que proceden ${ }^{108}$. Dicho elemento distintivo no se presenta si la pluralidad de infracciones corresponde a una unidad de ejecución, pues se trata de un supuesto que da cuenta de una única instancia o momento en el que se expresa una "afrenta al derecho, y que por ello no es señal de una particular "rebeldía" ${ }^{109}$. Así se explica su equívoca asociación con la imposición de una única sanción, cuya gravedad se incrementa en atención a la pluralidad de infracciones concurrentes ${ }^{110}$. Y también explica por qué se considera la misma regla para los casos de concurso medial, en atención a que se basa en una conexión que habilita a considerar el conjunto como parte de una misma y única ejecución o realización ${ }^{111}$, a pesar de que no son casos de unidad de acción o hecho en el sentido indicado ${ }^{112}$. "Qua delicta tot poenae" no platea una asociación entre delito y pena, sino que lo vincula a una noción más amplia que equivale a "realización", expresiva de un contexto en el

${ }^{101}$ ALVAREZ (2008), pp. 47-52. La reiteración delictiva daba lugar hasta ese momento a una pena de naturaleza más grave. El caso más conocido se vincula a la teoría del delito continuado (pena de muerte para el tercer hurto) cuya aplicación no distinguía un caso de "reincidencia" o de reiteración concursal. Sobre éste y otros ejemplos FERRINI (2017), p. 134. La asimilación de la reincidencia con una "circunstancia modificatoria" y su aplicación con carácter más general se asocia concretamente a la regulación de la determinación de pena con base en la legalidad, por el dato que aporta la "condena previa". Al respecto véase MALDONADO (2016a), pp. 115 y ss.

102 Véase al respecto SANZ (1986), pp. 44 y 46-51. Lo relevante de este "paso" es que permite advertir que en este autor no existía aun una estrecha vinculación entre pluralidad de hechos y acumulación de penas, en tanto da cuenta de casos en que dichos supuestos ameritan un régimen unificado (p. 48).

${ }^{103}$ SANZ (1986), pp. 50-51.

${ }^{104}$ Véase SANZ (1986), pp. 44 y 46-51. En este sentido, FONTECILLA (1956), pp. 78-79; CÁRDENAS (1973) (por ejemplo, en p. 27). BUSTOS (1962), pp. 102 y 105. Actualmente se aprecia en ORTIZ Y ARÉVALO (2013), pp. 317 y 346. Sobre la relación descrita SANZ (2012), p. 46. 105 En el sentido observado, por todos, ORTIZ Y ARÉVALO (2013), pp. 317 y 346; BUSTOS (1962), pp. 102 y 105 (con una panorámica de la época en cuanto a lo asentado de esta idea). Asimismo, véase SUÁREZ (2001), p. 108.

${ }^{106}$ Esta lectura literal también amerita otras objeciones. En lo fundamental es poco discutible que un delito pueda ser sancionado con variadas formas de reacción y, en el caso inverso, que una pluralidad de delitos pueda ser sancionado con una única pena. Así sucede en las penas copulativas y en las sanciones accesorias. La imposición de varias sanciones a un mismo delito ni siquiera habilita a considerar un bis in ídem. Al respecto HERNÁNDEZ (2014), p. 571; MAÑALICH (2018b), p. 559; MALDONADO (2016b), pp. 579-581; y OSSANDON (2018), pp. 963, 964 y 986.

${ }^{107}$ FERRINI (2017), p. 134

108 Véase FEUERBACH (1989), p. 123, en alusión específica a los "crímenes reiterados".

${ }^{109}$ La unidad que se describe se identifica en este caso como una "unidad de fin". Al respecto véase SANZ (1986), pp. 44 y 46. Implícito en FEUERBACH (1989), p. 124.

${ }^{110}$ En efecto, resulta errónea la asociación de esta unidad a un régimen penológico unitario. Así, en Groizard, Citado en SANZ (1986), p. 180, quien sostiene que "la unidad de acto moral que da vida al delito, hace lógica la imposición de una sola pena", pues nada impide la aplicación de un régimen de penas acumulativo o copulativo. Lo que se postula a partir de lo dicho es, en exclusiva, una consideración penológica diferenciada y comparativamente privilegiada.

${ }^{111}$ Admiten por ello ser calificados como casos de unidad de acción "en sentido funcional". Al respecto véase MAÑALICH (2005), p. 1039. Sobre esta base fueron en su tiempo erróneamente "asumidos" como casos de concurso ideal. Al respecto MUÑOZ (1986), pp. 338-339, en relación al planteamiento de Raimundo Del Rio, Labatut y otros).

112 De ahí que sea correcta la postura dominante que los identifica como casos de concurso real. Sobre ello véase supra nota № 79 . Hay que reconocer sin embargo que históricamente el tema no ha estado exento de controversia. Sobre las diversas posturas véase GUINARTE (1988-1989), pp. 160-162. 
que tiene lugar un delito (o varios) ${ }^{113}$. Lo dicho permite explicar una serie de equívocos que quedan bien ejemplificados en la llamada "teoría de la unidad" (predominante en Alemania en el Siglo XIX, a consecuencia del influjo de corrientes empíricas) ${ }^{114}$ bajo la cual se describe el concurso ideal como un caso de unidad de acción o de hecho pero además como una situación de "unidad de delito", cuya característica distintiva radicaría en la "particularidad" de que amerita una pluralidad de calificaciones jurídicas (penales) ${ }^{115}$. Asimismo, destaca también la idea -bastante extendida- de que el tratamiento unitario previsto para los casos de concurso ideal (asumido como privilegiado, en términos comparativos) encuentra su razón de ser en la necesidad de evitar un quebrantamiento (parcial) del principio non bis in ídem, bajo la premisa (configurada erróneamente) de que nadie puede ser sancionado dos veces por un mismo hecho (o por un "hecho único") ${ }^{116}$. Si bien nadie puede a estas alturas discutir la relevancia de dicho principio en el campo de la teoría concursal ${ }^{117}$, no parece que sea éste un caso en el que tenga aplicación, por la sencilla razón de que se trata de un límite que proscribe la valoración duplicada de una misma propiedad ${ }^{118}$ y no la valoración plural de propiedades diversas que se identifican en torno a un mismo supuesto de hecho ${ }^{119}$, que es lo que ocurre en estos casos en particular, pues, bajo esta perspectiva, el campo de la coincidencia o unidad es solo factual ${ }^{120}$.

Por sobre ello, lo dicho también pone de relieve que la noción reseñada resulta útil a los efectos que nos ocupan, en la medida que no se puede descartar a priori que el recurso a la rebeldía o una exteriorización de una voluntad contraria a derecho pueda tener incidencia en el ámbito de la determinación de las consecuencias que acarrea la responsabilidad penal (al margen, evidentemente, de las críticas que pueda suponer) ${ }^{121}$. Y también parece plausible afirmar dicha calificación con base en el dato que aporta la constatación de una pluralidad de realizaciones delictivas ${ }^{122}$. Así, el legislador contaría con un elemento de juicio que resultaría idóneo para asignar un tratamiento penológico determinado a quien da cuenta de una actitud renuente o rebelde frente a los mandatos jurídicos (como sucedería en los casos de concurso real) y que debe ser diferente al aplicable a quien "irrumpe voluntariamente en el campo del

${ }^{113}$ En este sentido véase LISZT (1914), pp. 169-170, quien detalla que en los casos en que el individuo ha infringido la ley en tiempos diversos para el derecho es como si se tratara en cada caso de delincuentes distintos. Por ello procede en dichos casos la pena que la ley le otorga a cada delito (en referencia explícita al principio "qua delicta tot poenae"). Es solo en este sentido es también correcta la estrecha asociación que se postula entre dicha máxima y el derecho penal de actos. ZAFFARONI et al. (2002), p. 851; RIGHI Y FERNÁNDEZ (2005), p. 321.

114 VAN WEEZEL (2021), p. 313.

115 Sobre la teoría de la unidad MAURACH et al. (1995), p. 520. Asimismo, véase la cita que se contiene en nota 33 precedente. Se advierte también con claridad en NÚÑEZ (1986), p. 24 y en LURATI (2018) p. 118.

${ }^{116}$ Al respecto, MALDONADO (2020), P. 748; asimismo, en el mismo sentido DÍAS (2013), p. 65, con amplia cita de autores de referencia (sin compartir el criterio). Asimismo, a los mismos efectos, véase SANZ (2012), p. 44 y MATUS (2005), p. 467. Entre los autores aludidos se cuenta reiteradamente a Mir, Cuerda y Puppe. Véase también OSSANDON (2018), p. 965, quien reconoce un "cierto efecto parcial del principio" fundado en la "cierta identidad" que ofrece el hecho. En un sentido similar, sostuve un criterio equivalente en MALDONADO (2014), p. 96, que hoy he abandonado.

${ }^{117}$ Al respecto véase ETCHEBERRY (1997), p. 109; NOVOA (2005), p. 220. ESCUCHURI (2004), pp. 26, 65 y, especialmente, 433 y ss.; ARCE (1996), pp. 22 y ss.; MUÑOZ (1986), p. 343; MAÑALICH (2005), p. 1025; MAÑALICH (2004), p. 485. MAÑALICH (2018c), p. 206; FERNÁNDEZ (2013), pp. 26 y 29; SERRANO (2017), p. 24; MATUS (2002), p. 30; MAÑALICH (2005), p. 1040; CARAMUTI (2018), p. 106; MAURACH et al. (1995), pp. 513, 515 y 516.

118 MAÑALICH (2004), p. 486; CID (1994), pp. 38 y 53; GARCÍA (1995), p. 229 (quien por ello lo asocia el al principio de identidad, en p. 43); ESCUCHURI (2004), p. 232; GARCÍA (2003), p. 178. Lo relevante es que la posibilidad de identificar una redundancia solo se produce con base en las valoraciones legislativas (MAÑALICH (2018b), p. 549).

${ }^{119}$ Resulta bastante evidente que un mismo sustrato puede ser objeto de múltiples valoraciones (GARCíA (1995), p. 232). Como indica Ossandón, una infracción al principio en estos supuestos solo es posible para quienes se basan en el contenido extensional. OSSANDON (2018), pp. 966-967. Véase también GARCÍA (1995), pp. 234-239. Sobre esta tendencia clásica en la doctrina italiana, GARCíA (1995), pp. 36 y ss.

${ }^{120}$ El punto central es que cada delito se estructura a partir de propiedades específicas, de forma que de una pluralidad de delitos se podrán igualmente identificar tantas como aquellas que los configuran, lo que sucederá con total independencia de que se adviertan o extraigan de un mismo contexto, elemento o supuesto fáctico. Por ello, no se puede sostener que en la sanción de cada delito ejecutado en unidad de hecho concurra una auténtica identidad de "fundamento" (conforme a la terminología tradicional) pues cada uno se basa en la valoración de propiedades específicas diversas. Al respecto, en torno al ámbito concursal en específico véase ROIG (2011), pp. 343 y ss.; ESCUCHURI (2004), pp. 92 y ss. y, más sintético, en OSSANDON (2018), p. 965.

$121 \mathrm{El}$ punto que se propone no se acota en modo alguno a la reincidencia. Baste tener en cuenta que son numerosos y considerablemente más amplios los efectos asociados a la reiteración delictiva. Al respecto véase, con detalle, MALDONADO (2016a), pp. 90-91.

${ }^{122} \mathrm{Al}$ respecto véase MALDONADO (2016a), pp. 97-99, en especial nota 26. 
derecho en un solo momento" ${ }^{123}$, en atención a que en este último caso se reprocha un "único acto o manifestación de voluntad contraria a derecho" 124 .

Contra esta aproximación se ha señalado que la rebeldía a la que se alude (como actitud o ánimo reprochable) solo se podría llegar a valorar en torno a aquello a través de lo que se exterioriza (en este caso, los respectivos delitos cometidos), de forma que no sería posible considerarla sino a través de las respectivas formas ejecutivas típicas ${ }^{125}$. Por ello no sería legítimo desprender dicho dato del contexto que aporta la constatación de una realización "plural", pues la desobediencia solo podría ser considerada en torno un concreto y específico contenido de lo injusto, en el sentido que sugiere el contenido atribuido al principio de "culpabilidad por el hecho" ${ }^{126}$. Estaría proscrito por ello calificar dicha actitud en torno a un contexto diverso o más general- Y menos aún, llegar a valorarla como mera actitud personal ${ }^{127}$.

A este respecto debemos tener en cuenta que desde nuestra perspectiva todo lo dicho es correcto y resulta plenamente válido si de lo que se trata es de fundar una atribución. No obstante, creo que nadie podría a estas alturas cuestionar que el proceso de determinación de sanciones opera en base a un ámbito de referencia más amplio acorde a su sentido y finalidades propias $^{128}$, en el que cabe considerar un mayor abanico de elementos de juicio ${ }^{129}$. Así se explica que los diversos sistemas penales reconozcan y hayan reconocido siempre efectos asociados a datos adicionales a lo injusto o a la culpabilidad y al dato que aporta la recaída o reiteración, en una constelación de supuestos que excede con mucho a la sola consideración de la llamada agravante de reincidencia ${ }^{130}$. En dichos casos, no parece posible objetar la consideración de este mismo tipo de contenidos en el campo de la teoría concursal, en tanto aporta un sentido claro y valorable en el ámbito de las consecuencias posibles de asignar a los casos de concurso real y concurso ideal ${ }^{131}$. Como indica Frister -en relación precisamente al caso que nos ocupa- "el ilícito no es equivalente en la medición de la pena a los intereses individuales protegidos por los bienes jurídicos, sino al interés público en la vigencia de las normas que los protegen. Por ello es posible considerar más grave la contradicción plural, realizada mediante una pluralidad de hechos, que los casos de unidad" 132 .

De esta forma, si el análisis se lleva a cabo en torno a un sistema que no aplica ningún tipo de efecto a la reiteración delictiva (retributivo puro u ortodoxo), la justificación y la propia distinción propuesta carecería de sentido, de forma que debería considerarse la misma sanción (al menos por esta razón) para todo caso de concurso de delitos. Lo propio sucede respecto de quienes entienden que en la medición de la pena solo se pueden valorar contenidos que inciden en lo injusto o en la culpabilidad. Respecto de ambos casos solo nos queda dejar constancia de que no conocemos sistemas con tales características.

\footnotetext{
${ }^{123}$ BUSTOS (1962), pp. 64 y 66

${ }^{124}$ ARCE (1996), pp. 55 a 57, en referencia a Carrara. En un sentido equivalente LURATI (2018), p. 118, en cita a Nuñez (quien entiende que en el fondo se trata de "una única culpabilidad"). A nivel general ROIG (2011), pp. 353-355 (con cita de autores de referencia). En un sentido equivalente Groizard (citado en SANZ (1986), p. 180) y FONTECILLA (1956), pp. 78-79.

${ }^{125}$ ROIG (2011), pp. 355-356, en el campo del concurso de delitos.

${ }^{126}$ En el mismo sentido ESCUCHURI (2004), p. 92. Asimismo, SUÁREZ (2001), p. 59.

${ }^{127}$ Lo dicho explica por qué el criterio también aparece en doctrina vinculado a la constatación de una mayor o menor energía criminal, que incide en la culpabilidad (teniendo en cuenta que en los casos de unidad "se ha debido vencer solo una vez el impulso criminal"). En este sentido ROXIN (1997), p. 943; JESCHECK Y WEIGEND (2014), p. 1073. Se cita asimismo, en ESCUCHURI (2004), p. 88.

${ }^{128}$ En un sentido equivalente VAN WEEZEL (2021), p. 310 (si bien en torno a lo que cuenta en forma precisa como "acción" en la teoría del delito y en la determinación de la pena).

129 En términos acríticos, ETCHEBERRY (1997), pp. 15 y ss.; NOVOA (2005), pp. 10-11; CURY (2007), pp. 471-472; ORTIZ Y ARÉVALO (2013), pp. 266-274 y 363-367. En términos más específicos, BESIO (2011), pp. 405 y ss. El tema no ha estado ajeno al debate, en especial, en atención a que un planteamiento más formalista o extremo de la culpabilidad o retribución lleva a descartar la posibilidad de ocupar referentes diversos a los que ofrece el contenido de injusto o la culpabilidad. En la actualidad dicho debate se ha centrado en torno a las exigencias y funciones asociadas a la proporcionalidad. Sobre la problemática general véase SILVA (2007), pp. 3, 5 y 8-10. Otra cosa es que la valoración de contenidos ajenos al injusto o la culpabilidad sean a su vez desvalorados y puedan ser atribuidos, cuestión que se comparte.

${ }^{130}$ A este respecto véase, con detalle, MALDONADO (2016a), pp. 90, 91 y 109. Asimismo, debe tenerse en cuenta la amplia aceptación de reglas especiales aplicables al "primerizo", lo que, de suyo, supone la legitimación de un tratamiento diferencial respecto de quien no puede reclamar dicho calificativo. Al respecto véase MALDONADO (2016a), pp. 104 y ss.

${ }^{131}$ En relación al concurso real véase MALDONADO (2016a), pp. 115 y ss.

132 FRISTER (2016), p. 668.
} 


\section{Precisiones finales relevantes de considerar}

Lo dicho obliga en cualquier caso a explicitar la forma como se podría dar operatividad al criterio propuesto. A fin de cuentas, no se trata solo de señalar qué significa que dos delitos se ejecuten en unidad de hecho o de acción sino de identificar en una concreta y determinada instancia de realización que indique en forma más precisa "qué aspectos del mundo cuentan como tal". Lo dicho supone reconocer que a dicho respecto la dimensión naturalística juega un papel (según advertimos algunas líneas atrás), pues se trata del campo o ámbito en el que se refleja y ejemplifica la correspondiente unidad ${ }^{133}$. En este sentido resulta inevitable arribar a una conclusión que de cuenta de una delimitación espacio-temporal, que tiene principio y final y que corresponde a un fragmento de la realidad (que cuenta como un ejemplo o "caso" de cierta acción o hecho) ${ }^{134}$. Otra cosa es que para llegar a ello se requiera de una plantilla o criterios que permitan desarrollar dicha precisión o delimitación ${ }^{135}$.

Conforme a lo dicho este reflejo o expresión tangible debe ser uno en el que se afirman las propiedades que permiten identificar una única instancia de "afrenta al derecho", lo que supone tomar como referente lo que cuenta como una acción del tipo o clase del delito de que se trate, con base en "los" delitos concurrentes (ambos a la vez). Ello supone que las propiedades correspondientes a cada infracción (según el caso) juegan un papel, pero que al mismo tiempo no son suficientes para agotar la operación, lo que, según hemos visto, implica ocupar una noción de hecho o acción diversa y más amplia. No hay que olvidar que no se trata de señalar un sustrato que equivale una acción o hecho que se corresponda con un delito sino de identificar cuándo dos o más unidades de esta clase (delictivas) se advierten como parte de un fragmento de la realidad que vale como una misma ejecución.

Esta doble consideración explica por qué no es posible desarrollar esta operación en abstracto, con miras a identificar una noción "genérica" de hecho o acción (a estos efectos) y menos aún una que sea única o uniforme para todo caso de concurso ideal. La conclusión necesariamente estará condicionada por la realidad de cada caso en particular, conforme a los caracteres que describan aquello que pueda llegar a identificarse como una "realización" o "ejemplificación "de cada uno de los supuestos delictivos concurrentes. Por ello, no se trata solo de considerar las exigencias o propiedades que se extraen de las respectivas nociones de delito, sino de concretizarlas en torno a la forma que asumen en un caso concreto, a partir del resultado del correspondiente proceso de subsunción.

Si esto es así -y aquí está la clave- se puede sostener una unidad de hecho (en el sentido indicado) en torno a un ámbito en el que se advierta la coincidencia a los presupuestos fácticos que están en la base de las propiedades que equivalen al proceso ejecutivo de todas y cada una de las hipótesis concurrentes ${ }^{136}$, lo que, en definitiva, coincide con el "ámbito de referencia en el que se superpone la realización de las diferentes descripciones típicas"137.

Por sobre lo dicho resulta conveniente agregar dos precisiones adicionales. Lo primero es poner de relieve que la idea de realización no se corresponde con un supuesto que deba ser expresivo de la totalidad de las exigencias de los tipos de hecho punible de que se trate (ocupando como referente lo que es el delito en forma completa), pues el ejercicio u operación a desarrollar se orienta a la precisión de aquello que cuenta como expresión de una determinada

\footnotetext{
${ }^{133}$ Como indica FLETCHER (2008), p. 374 la dimensión social o comunicativa de una acción lleva a abandonar la idea de centrarse en la intención, sino en la percepción que comunica una determinada realización en el mundo. Hay que tener en cuenta, según ya hemos procurado resaltar, que la dimensión naturalística no es útil para aportar razones o criterios que alimenten dicha definición, sino que se mueve en el campo de su reflejo material. Lo dicho no implica que en dicha determinación se abandone la perspectiva de sentido pues lo que cuenta como acción o hecho vendrá siempre condicionado por una definición conceptual fundada en un conjunto de propiedades a interpretar. Se debe diferenciar por ello lo que es una acción y lo que cuenta, en el ámbito empírico, como tal.

134 MIR (2005), pp. 625 y 626. En Chile, POLITOFF et al. (2003), p. 445.

135 En concreto, el concepto de acción opera como una auténtica "plantilla" que recorta lo empírico. Al respecto POLITOFF et al. (2003), p. 445.

${ }^{136}$ SANZ (2012), p. 41; STRATENWERTH (2005), p. 550.

137 SANZ (2012), p. 41.
} 
"ejecución" (a "algo que se hace") ${ }^{138}$ que refleje la "manifestación de una voluntad contraria a derecho"139. De esta forma no se alude al fragmento de tiempo que alcanza a la total y completa ejecución de cada uno de los delitos cometidos, sino de una expresión más acotada, relativa a lo que cuenta como parte de los respectivos "actos de ejecución" (expresión acuñada en la doctrina alemana). Es decir, el referente lo aportan las propiedades correspondientes a las "actividades mediante las cuales se realiza el tipo de delito" ${ }^{140}$. De esta forma, el sustrato debe corresponder a un fragmento de la realidad cuyo inicio se puede identificar en torno al límite que separa "la preparación impune y la tentativa punible" ${ }^{141}$ y que culmina con aquello que cuenta como último acto de ejecución, equivalente a la realización de la correspondiente forma o modo de ejecución y, en delitos de resultado, a la tentativa acabada (o, en nuestro modelo, a la frustración) ${ }^{142}$.

En segundo lugar, hay que tener en cuenta que lo dicho no demanda corroborar una absoluta identidad entre los correspondientes sustratos, por la sencilla razón de que el objeto de referencia que se pretende no se construye a partir de la idea de una misma acción o hecho (en el sentido de los correspondientes delitos), sino de una que valga como instancia de realización de ambos (o todos ellos) a la vez ${ }^{143}$. Debe por ello dar cuenta de la identidad del proceso ejecutivo que está en la base de los tipos concurrentes (de todos) y no de las respectivas "acciones ejecutivas" que se asocien e cada uno de ellos en forma individual ${ }^{144}$. De ahí que se deba reconocer la unidad de hecho aun en casos de solapamiento o implicación (fáctica) parcial, como sucede en aquellos en que el sustrato que corresponde a la realización de uno de los delitos concurrentes se superpone con la del otro delito (u otros delitos) que conforman el respectivo concurso ${ }^{145}$.

\section{BIBLIOGRAFÍA CITADA}

Alvarez Pozo, María De la Palma (2008): "La génesis de la teoría del Concurso de delitos en el ordenamiento jurídico español”, en: Cuadernos de Política Criminal (№ 94), pp. 33 a 70.

ARCE AgGeo, Miguel Ángel (1996): Concurso de delitos en materia penal (Buenos Aires, Editorial Universidad).

\footnotetext{
${ }^{138}$ A este respecto véase GUZMÁN Y FERNÁNDEZ (2011), p. 35. Asimismo, FERNÁNDEZ (2013), pp. 36-37, en cita a Radbruch.

${ }^{139}$ Como acertadamente sostiene GARCíA (1995), p. 128 (en cita a Kindhauser): "la unidad de situación de motivación debe reflejarse en la objetivización de dicha motivación, que se expresa en una determinada unidad de ejecución".

140 SANZ (1986), p. 152.

141 STRATENWERTH (2005), p. 550.

${ }^{142}$ Con ello se deben rechazar aquellas posturas que llegan a situar el límite en torno a las manifestaciones de lo que cuenta como agotamiento del delito, como en FRISTER (2016), pp. 671-672 o en ROXIN (1997), pp. 969-970. Asimismo, en torno a aquellos casos en que uno de los delitos supone la constatación de una tendencia interna trascendente que luego se realiza en el otro delito (ROXIN (1997), p. 970). Asimismo, tampoco parece acertada la doctrina -dominante en Alemania- que rechaza unidad de hecho o acción en casos de superposición parcial en tentativa (ROXIN (1997), pp. 970-971) y que también encuentra adherentes en España (como VIVES (1981), p. 17).

${ }^{143}$ A este respecto véase MIR (2005), p. 626. Por esta razón no se debe descartar a priori la idea de "simultaneidad", en el sentido indicado. A este respecto es correcto asumir que "simultaneidad no es sinónimo de unidad" (CARAMUTI (2018), pp. 107, 209 y 213) pero solo en cuanto no se trata de un factor suficiente por sí mismo para dar cuenta de una unidad y en cuanto no es el único contenido que permite a considerar a un conjunto como parte de un todo más amplio (y en ese sentido, único). Por esta razón parece acertado que se califique la idea de simultaneidad como un indicio (CARAMUTI (2018), p. 42).

${ }^{144}$ SANZ (1986), p. 152. Lo dicho explica por qué un importante sector de la doctrina alemana reconoce una unidad de acción (hecho o ejecución) tras los casos tratados bajo el llamado efecto de abrazadera del concurso ideal. Constituyen hipótesis en las que se afirma la unidad de delitos que no presentan conexión alguna (ni siquiera espacio-temporal) pero que se dejan apreciar como una unidad por la concurrencia de un tercer delito que presenta elementos en común respecto de ambos. Al respecto, MAURACH et al. (1995), pp. 570573; ROXIN (1997), pp. 974 y ss.; STRATENWERTH (2005), p. 551; MAÑALICH (2005), pp. 1037-1038. Esta doctrina es fuertemente rechazada en España (a pesar de que se acoge a idea de la coincidencia en la acción puede ser parcial). Al respecto véase ROIG (2011), pp. 131 y ss. en el mismo sentido ESCUCHURI (2004), p. 89; SANZ (2012), p. 41. En Chile alude al concepto CURY (2007), p. 651, pero en referencia a los casos de unidad jurídica de acción que reúnen un conjunto de acciones en sentido natural.

${ }^{145}$ Así se reconoce por un importante sector de la doctrina alemana que se califica como dominante (JESCHECK Y WEIGEND (2014), p. 1076; ROXIN (1997), pp. 965 y ss., y, en especial, en p. 967; STRATENWERTH (2005), p. 550). Constituye, también el criterio dominante en España (ROIG (2011), pp. 129 y ss.); SANZ (2012), p. 41. Véase asimismo, con carácter más general, MAÑALICH (2005), p. 1037. La crítica se asocia a propuestas que se basan en un objeto de referencia que equivale a la "identidad de la acción" y no su unidad, de forma que toda referencia a la simultaneidad resulta superflua. Las menciones usuales se orientan a casos como el uso de un escudo humano mientras se dispara o el golpe con las dos manos a personas diversas (WELZEL (1993), pp. 273-274). Al respecto véase JAKOBS (1997), p. 1075; ZAFFARONI et al. (2002), p. 866.
} 
ARTAZA VARela, Osvaldo (2021): "La regularidad como factor relevante para la aplicación de la regla de preferencia consunción. Análisis critico”, en: Maldonado Fuentes, Francisco (Coord.), Concurso de delitos. Problemas fundamentales (Valencia, Editorial Tirant lo Blanch), pp. 95-118.

Besio HeRnández, MARTIn (2011): Los criterios legales y judiciales de individualización de la pena (Valencia, Editorial Tirant lo Blanch).

Bustos Ramírez, Juan (1962): Concurso ideal de delitos, Memoria de Prueba para optar al Grado de Licenciado en Ciencias Jurídicas y Sociales (Santiago de Chile, Editorial Universitaria, Universidad de Chile).

CAlderón Cerezo, Angel (1995): “El concurso real de delitos y sus consecuencias punitivas", en: Calderón Cerezo, Angel (Ed.) Unidad y pluralidad de delitos, Cuadernos de Derecho Judicial, Consejo General del Poder Judicial (Madrid, Ediciones del Consejo General del Poder Judicial), volumen 2, pp. 137-187.

CARAmUti, Carlos (2013): "Algunas cuestiones concursales en torno a los tipos penales de trata de personas", en: VV.AA., Anuario de Derecho Penal 2012 (Buenos Aires, Editorial AD-HOC), pp. 47 a 60.

CARAmuti, Carlos (2018): Concurso de delitos, 3ạ edición (Buenos Aires, Edit. Hammurabi).

CÁRDENAS, RAúl (1973): El concurso ideal para el Código Penal tipo para la América Latina (México, Ediciones Botas).

Caruso Fontan, María Viviana (2018): Unidad de acción y delito continuado (Valencia, Editorial Tirant lo Blanch).

CASTELLó NICAS, NURIA (2000). El concurso de normas penales (Granada, Edit. Comares).

CID MolinÉ, JosÉ (1994): “Notas acerca de las definiciones dogmáticas de concurso de delitos”, en: Anuario de Derecho Penal y Ciencias Penales (№ 47), pp. 29-64.

COUSO SALAS, JAIME (2006): Fundamentos del derecho penal de culpabilidad. Historia teoría y metodología (Valencia, Edit. Tirant Lo Blanch).

CUello CONTRERAS, JoAquín (1979): "La frontera entre el concurso de leyes y el concurso ideal de delitos: la función de la normativa concursal (I)”, en: Anuario de Derecho Penal y Ciencias penales (Vol. 32, № 1), pp. 45-92.

CUeRdA RieZU, ANTONIO (1992): Concurso de delitos y determinación de la pena: análisis legal, doctrinal y jurisprudencial (Madrid, Edit. Tecnos).

Cuerda Riezu, ANTONio (1997). “La unidad de delito en la jurisprudencia del TS”, en: Silva Sánchez, Jesús (Ed.), Política criminal y nuevo derecho penal, Libro homenaje a Roxin (Barcelona, Edit. Bosch), pp. 341-354.

CURY URZÚA, EnRIQue (2007): Derecho Penal. Parte General (Santiago, Ed. Universidad Católica de Chile).

DE DOU, RAMÓN LÁZARO (1800): Instituciones del derecho público general de España con noticia del particular de Catalunya y de las principales reglas de gobierno en cualquier Estado (Madrid, Edit. Oficina de don Benito García y Compañía), tomo II.

DE LA RUA, JORGE (2013): “Cuestiones actuales referidas al concurso de delitos: La regulación de los concursos en el Código Penal y en el proyecto 2007", en: VV.AA., Anuario de Derecho Penal 2012 (Buenos Aires, Editorial AD-HOC), pp. 15 a 24.

ESCUCHURI, ESTRELLA (2004): Teoría del concurso de leyes y de delitos: bases para una revisión crítica (Granada, Edit. Comares).

EtCHeberRy, AlfRedo (1964): El concurso aparente de leyes penales (Santiago, Editorial Jurídica de Chile).

ETCHEBERRY, AlfREDo (1997): Derecho Penal, 3o edición revisada y actualizada (Santiago, Editorial Jurídica de Chile).

FernANDEZ, GonzAlo (2013): “Criterio de determinación de la unidad de hecho en el concurso de delitos", en: VV.AA., Anuario de Derecho Penal 2012 (Buenos Aires, Edit. AD-HOC), pp. 25-46.

FERRINI, CONTARdo (2017): Derecho penal romano (Barcelona, Edit. Marcial Pons).

Feuerbach, PAul AnSELm (1989): Tratado de Derecho Penal, común vigente en Alemania, traducción de la 14ạ ed. Alemana (Traducc. Eugenio R. Zaffaroni e Irma Egemeier, Buenos Aires, Edit. Hammurabi). 
Fletcher, George (2008): Gramática del Derecho Penal (Buenos Aires, Editorial Hammurabi).

FonteCILLA RIQUeLME, RAFAel (1956): Concursos de delincuentes, de delitos y de leyes penales y sus principales problemas jurídicos (Santiago, Editorial Jurídica de Chile).

Frister, Helmut (2016): Derecho Penal. Parte General, traducción de la 4ạ ed. Alemana (Traducc. Marcelo Sancinetti, Buenos Aires, Edit. Hammurabi).

García Alberó, Ramón (1995): Non bis in ídem material y concurso de leyes penales (Barcelona, Edit. Cedecs).

García García, José Alberto (2003): “Análisis sobre la aplicación de las doctrinas de doble exposición y concurso de delitos", en: Revista de Derecho Puertoriqueño (№ 42), pp. 169-180.

Garrido Montt, Mario (2007): Derecho Penal. Parte General, 4a edición (Santiago, Edit. Jurídica de Chile).

Gómez De la Cerna, Pedro y Montalbán, Juan Manuel (1851): Elementos del Derecho Civil y Penal de España, precedidos de una reseña histórica, 4ạ edición (Madrid, Imprenta de la Compañía Impresores y Libreros del Reino).

GonZÁLEZ LAGIER, DANIEL (2015): Conceptos básicos del derecho (Barcelona, Edit. Marcial Pons).

Guinarte Cabada, Gumersindo (1988-1989): "El concurso "medial" de delitos", en: Estudios penales y criminológicos (№ 13), pp. 153-206.

GuZMÁn DÁlBORA, José LUIS y FERnÁNDEZ, GonZAlo (2011): “Estudio introductorio”, en: Radbruch, Gustav, El concepto de acción y su importancia para el sistema del derecho penal (Montevideo / Buenos Aires, Edit. BdeF), pp. 1-42.

HeRnÁNDEZ BAsualto, HÉCtor (2014): “Actividad administrativa, procedimiento sancionatorio-administrativo y proceso penal: algunas necesidades de coordinación legal”, en: Arancibia Mattar, Jaime y Alarcón Jaña, Pablo (Coords.), Sanciones Administrativas. X Jornadas de Derecho Administrativo, Asociación de Derecho Administrativo (Santiago, Edit. Thomson Reuters), pp. 567-586.

JAKOBS, GüNTHER (1997). Derecho Penal. Parte General. Fundamentos y Teoría de la Imputación, 2a edición corregida (Madrid, Edit. Marcial Pons).

Jescheck, Hans Heinrich y Weigend, Thomas (2014): Tratado de Derecho Penal. Parte general, traducción de la 5a edición (Traducc. Miguel Olmedo, Lima, Edit. Instituto Pacífico).

JOSHI JUBERT, UJALA (1992): “Unidad de hecho y concurso medial de delitos", en: Anuario de Derecho Penal y Ciencias Penales (Tomo 45, Fasc. 2), pp. 613-636.

Labatut Glena, Gustavo (1983): Derecho Penal, 7ạ edición actualizada (Santiago, Editorial Jurídica de Chile), tomo II.

LISZT, FRANZ Von (1914): Tratado de Derecho Penal, traducción de la 18a edición (Traducc. Quintiliano Saldaña, Madrid Instituto Editorial Reus).

LURATI, CARINA (2018): El sistema de pena única en el Código Penal Argentino, 2a edición ampliada y actualizada (Buenos Aires, Edit. Rubinzal-Culzoni).

MALDONAdO FuenteS, FRANCISCO (2013): “Reincidencia y responsabilidad penal de adolescentes", en: Estudios de Derecho Penal Juvenil. Informes en Derecho (Santiago, Ediciones de la Defensoría Penal Pública), pp. 169212.

MALDONAdO FUentes, FRANCISCO (2014): “Consideraciones sobre la producción de resultados de riesgo general o de una multiplicidad de resultados lesivos a partir de la ejecución de una sola conducta delictiva en el derecho chileno. A propósito del desempeño en el tráfico rodado", en: Revista Doctrina y Jurisprudencia Penal, edición especial (Santiago, Edit. Thomson Reuters), pp. 77-100.

Maldonado Fuentes, Francisco (2015): “Delito continuado y concurso de delitos", en: Revista de Derecho de la Universidad Austral de Valdivia (Vol, XXVIII, № 2), pp. 193-226.

Maldonado Fuentes, Francisco (2016a): "Reiteración y reincidencia: conceptos y fundamento", en: Maldonado Fuentes, Francisco (Coord.), Reincidencia y concurso de delitos (Montevideo / Buenos Aires, Edit. BdeF), pp. 89-145. 
Maldonado Fuentes, Francisco (2016b): “Reiteración y concurso de delitos. Consideraciones sobre el artículo 351 del Código Procesal Penal a partir de la teoría general del concurso de delitos en el derecho chileno", en: Cárdenas, Claudia y Ferdmann, Jorge (Coords.), El Derecho Penal como teoría y como práctica. Libro Homenaje al Prof. Alfredo Etcheberry (Santiago, Editorial Thomson Reuters Chile), pp. 549-607.

MAÑALICH RAFFo, JuAn PABLo (2004): “Asperación de la pena bajo el régimen del concurso real”, en: Revista de Derecho de la Universidad Adolfo Ibáñez (№ 1), pp. 246-248.

RAFFO, JUAN PABLo (2005): “El concurso de delitos: bases para su reconstrucción en el derecho penal de Puerto Rico", en: Revista Jurídica de la Universidad de Puerto Rico (№ 74), pp. 1021-1211.

MAÑALICH RAFFO, JUAN PABLO (2014): Norma, causalidad y acción. Una teoría de las normas para la dogmática de los delitos de resultado puro (Barcelona, Edit. Marcial Pons).

MAÑALICH RAFFo, JUAN PABLo (2018a): “El principio ne bis in ídem como estándar de derecho sancionatorio, en el derecho penal chileno", en: Mañalich Raffo, Juan Pablo, Estudios sobre la fundamentación y determinación de la pena (Santiago de Chile, Edit. Thomson Reuters), pp. 67-103.

MaÑalich RAFFo, JuAN PABlo (2018b): "El principio ne bis in idem entre el Derecho penal y el derecho administrativo sancionatorio", en: Mañalich Raffo, Juan Pablo, Estudios sobre la fundamentación y determinación de la pena (Santiago de Chile, Edit. Thomson Reuters), pp. 105-131.

MAÑALICH RAFFO, JUAN PABLO (2018c): "El concurso aparente como herramienta de cuantificación penológica de hechos punibles", en: Mañalich Raffo, Juan Pablo, Estudios sobre la fundamentación y determinación de la pena (Santiago de Chile, Edit. Thomson Reuters), pp. 171-211.

Matus AcuñA, JeAn PierRe (1999): “Aportando a la reforma penal chilena. Algunos problemas derivados de la técnica legislativa en la construcción de delitos impropios: el error y el concurso", en: Revista lus et Praxis (Vol. 5, № 2), pp. 63-113.

MATUs ACUÑA, JeAn PIERRE (2000): “La teoría del concurso (aparente) de leyes en la dogmática alemana, desde sus orígenes hasta el presente (primera parte)”, en: Revista lus et Praxis (Vol. 6, № 2), pp. 195-371.

Matus Acuña, JeAn PierRe (2002): "La teoría del concurso aparente de leyes penales el resurgimiento de lay en principio desplazada", en: Revista de la Universidad Católica del Norte (№ 9), pp. 27-68.

Matus Acuña, JeAn PieRre (2005): "Los criterios de distinción entre el concurso de leyes y las restantes figuras concursales en el Código Penal español de 1995, en: Anuario de Derecho Penal y Ciencias Penales (Vol. 58, № 2), pp. 463-494.

Maurach, Reinhart; Gössel, Karl Heinz y Zipf, Heinz (1995): Derecho Penal. Parte General (Traducc. Bofill Genzsch, Buenos Aires, Edit. Astrea), tomo II.

Merkel, Adolf (2014): Derecho Penal. Parte General, reimpresión (Montevideo-Buenos Aires, Edit. BdeF).

Mezger, Edmundo (1955): Tratado de Derecho Penal (Madrid, Edit. Revista de Derecho Privado), tomo I.

MeZger, Edmundo (1958): Derecho Penal. Libro de Estudio, Parte general, traducción de la 6ạ edición alemana (Traducc. Conrado Finzi, Buenos Aires, Editorial Bibliografía Argentina).

Mir PUIG, SANTIAgo (2005): Derecho Penal. Parte General (Barcelona, Edit. Reppertor).

Muñoz HORMENT, Humberto (1986): “Contribución al estudio de la teoría de los concursos de delitos”, en: Revista Chilena de Derecho (Vol. 13), pp. 335-381.

Nino, Carlos SAntiago (1972): El concurso en el derecho penal: Criterios para clasificar los casos de varios hechos o de varias normas en la calificación penal de una conducta (Buenos Aires, Editorial Astrea).

Novoa Monreal, Eduardo (2005): Curso de Derecho Penal chileno, 3a edición (Santiago, Edit. Jurídica de Chile).

NúÑEZ, RICARDO (1986): “El problema del concurso de delitos”, en: Opúsculos de Derecho Penal y Criminología (№ 12), pp. 7-25.

Ortiz Quiroga, LUis y Arévalo, JAVIer (2013): Las Consecuencias jurídicas del delito (Santiago de Chile, Editorial Jurídica de Chile). 
Ossandon W., MAgdalena (2018): “El legislador y el Principio ne bis in ídem”, en: Revista Política criminal (Vol. 13, № 26), pp. 952-1002.

PACHECO, JoAquín Francisco (1888): El Código penal concordado y comentado, 6a edición (Madrid, Edit. Imprenta y Fundición de Manuel Tello).

Palma Herrera, José Manuel (2004): Los actos copenados (Madrid, Edit. Dykinson).

Peñaranda Ramos, EnRIQUe (1991): Concurso de leyes, error y participación en el delito (Madrid, Edit. Civitas).

PESSOA, NELSON (2018): Teoría de la unidad y pluralidad delictiva. Estudio del múltiple encuadre típico (Buenos Aires, Edit. Rubinzal-Culzoni).

Politoff, Sergio; Matus, Jean Pierre y Ramírez, Cecilia (2003): Lecciones de Derecho Penal. Parte General (Santiago, Editorial Jurídica de Chile).

PosAda MAYA, RICARDo (2008): "El Concurso de conductas punibles en el ordenamiento penal colombiano" en: Posada Maya, Ricardo (Coord.), Temas de Derecho Penal (Bogotá, Edit. Universidad de Los Andes), pp. 75-111.

RADBRUCH, GustaV (2011): El concepto de acción y su importancia para el sistema del derecho penal (Montevideo / Buenos Aires, Edit. BdeF).

Reyes Romero, ItAlo (2016): “El cuasidelito con resultado múltiple”, en: Cárdenas, Claudia y Ferdmann, Jorge (Coords.), El Derecho Penal como teoría y como práctica. Libro Homenaje al Prof. Alfredo Etcheberry (Santiago, Editorial Thomson Reuters Chile), pp. 455-499.

Righi, Esteban y FernándeZ, Alberto (2005): Derecho penal. La ley El delito. El proceso y la Pena (Buenos Aires, Edit. Hammurabi).

RoIg TORRES, MARGARITA (2011): El concurso ideal de delitos (Valencia, Editorial Tirant Lo Blanch).

Roxin, Claus (1997): Derecho Penal. Parte General. Fundamentos. La estructura de la Teoría del delito (Madrid, Edit. Civitas), tomo I.

SAnz Moran, Angel (2012): Unidad y pluralidad de delitos: La teoría del concurso en Derecho Penal, serie Derecho Penal (México, Edit. Ubijus.

SANZ MORAN, ÁNGEL José (1986): El concurso de delitos: aspectos de política legislativa (Valladolid, Universidad de Valladolid, Secretariado de Publicaciones).

SerRano Gonázalez De Murillo, José (2017): El concurso de normas y el concurso de delitos en el Libro II del Código Penal (Barcelona, Edit. Marcial Pons).

SILVA SANCHEZ, Jesús MARía (2003): “¿Qué queda de la discusión tradicional sobre el concepto de acción?, en: Silva Sánchez, Jesús María, Normas y acciones en Derecho Penal (Buenos Aires, Edit. Hammurabi), pp. 4166.

SILVA SANCHEZ, Jesús MARÍA (2007): “La teoría de la determinación de la pena como sistema (dogmático): un primer esbozo", en: Indret, Revista para el Análisis del Derecho (№ 2), pp. 1-15.

SUÁREZ LóPEZ, JosÉ MARÍA (2001): El concurso real de delitos (Madrid, Editoriales de Derecho Reunidas, EDERSA).

Stratenwerth, Günter (2005): Derecho Penal. Parte General I. El hecho punible, traducción 4a edición totalmente reelaborada (Traducc. Manuel Cancio y Marcelo Sancinetti, Buenos Aires, Edit. Hammurabi).

VÁsquez MATOS, José (1996): “Doble exposición o concurso de delitos”, en: Revista de Derecho Puertoriqueño (№ 65), pp. 205-223.

ViVes ANtón, TOMAS SALVAdor (1981): La estructura de la teoría del concurso de infracciones (Valencia, Universitat de Valencia).

Welzel, Hans (1993): Derecho Penal Alemán, traducción 11a edición (Traducc. Juan Bustos y Sergio Yáñez, Santiago de Chile, Edit. Jurídica de Chile).

Van Weezel, Alex (2021): “Unidad de hecho concursal”, en: Maldonado Fuentes, Francisco (Coord.), Concurso de delitos. Problemas fundamentales (Valencia, Editorial Tirant lo Blanch), pp. 301-330. 
Wessels, Johannes; Werner, Beulke y Satzger, Helmut (2018): Derecho Penal. Parte general. El delito y su estructura, 46a edición alemana (Lima, Edit. Instituto Pacífico).

Zaffaroni, Eugenio; Alagia, Alejandro y Slokar, Alejandro (2002): Derecho Penal. Parte General, 2a edición (Buenos Aires, Edit. Ediar). 